PALAVRAS. Revista de Epistemología, Metodología y Ética del Psicoanálisis

ISSN: 2468-9831

www.revistas.unlp.edu.ar/palavras

palavras@outlook.com.ar

Argentina

\title{
EL DESEO HOMOSEXUAL ES UNIVERSAL
}

DOI $10.24215 / 24689831 \mathrm{e} 034$

Mario Mieli

Cómo citar este artículo:

Mieli, M. (2019). El deseo homosexual es universal (Ariel Martinez, trad.). Palauras.

Revista de Epistemología, Metodología y Ética del Psicoanálisis, 5, 125-188.

Recuperado de www.revistas.unlp.edu.ar/palavras 


\title{
EL DESEO HOMOSEXUAL ES UNIVERSAL
}

\author{
Autor: Mario Mieli \\ Traducción: Ariel Martínez* \\ Título original: II Desiderio omosessuale è universale. Publicado en: Mieli, M. (1977). Elementi di critica \\ omosessuale. Torino: Giulio Einaudi editore.
}

\section{E1 movimiento gay frente a la represión}

\section{Los movimientos homosexuales contemporáneos han surgido en}

países donde el capital ha alcanzado la etapa de su dominio real ${ }^{1}$. Sin

\footnotetext{
* Centro Interdisciplinario de Investigaciones en Género (CInIG, IdIHCS UNLP/CONICET). Argentina. Mail: amartinez@psico.unlp.edu.ar

1 Cfr. KARL MARX, Il capitale: Libro I, cap. VI inedito. Risultati del processo di produzione immediato, La Nuova Italia, Firenze 1969; además: JACQUES CAMATTE, $l$ capitale totale, Dedalo Libri, Bari 1976. En el cap. VI, Marx describe las dos fases del desarrollo social del capitalismo: la sumisión formal del trabajo al capital (dominio formal) y la sumisión real del trabajo al capital (dominio real).
}

En cuanto al dominio formal, escribe: 'el proceso laboral se convierte en un medio del proceso de valoración, del proceso de auto-valoración del capital, de la fabricación de plusvalía. El proceso de trabajo está sometido (subsumiert) al capital (es su propio proceso) y el capitalista ingresa al proceso como gerente (Dirigent), director (Leiter); para él es al mismo tiempo un proceso inmediato de explotación del trabajo externo. A esto lo llamo la sumisión formal (formelle Subsumtion) del trabajo al capital. Es la forma general de todo proceso de producción capitalista, pero también es una forma particular junto con el modo de producción especificamente capitalista desarrollado, ya que este último implica el primero, pero el primero no implica (involviert) necesariamente al último'. Esta sumisión formal está vinculada a la producción de plusvalía absoluta. 'El capitalista, escribe Camatte, no puede lograr un valor mayor si no es prolongando la jornada laboral. Todavía no ha derrocado la base misma de la sociedad. Por el momento, se ha limitado a reemplazar a otro explotador. El dominio formal, por lo tanto, se caracteriza esencialmente por este elemento: desde el principio, el capitalismo se distingue de otros modos de producción por el hecho de que no se basa simplemente en una apropiación de plusvalía, sino en su creación'.

En cuanto al dominio real (sumisión real del trabajo al capital), Marx escribe: 'Existe la característica general de la sumisión formal, es decir, la subordinación directa (Unterordnung) del proceso laboral al capital, cualquiera que sea la técnica empleada en él. Pero sobre esta base hay un modo de producción tecnológica y no solo tecnología específica, que modifica la naturaleza real del proceso de trabajo y sus condiciones reales -el modo de producción capitalista. Solo desde el momento en que este modo de producción entra en acción se produce la sumisión real (reale Subsumtion) del trabajo al capital'. Es con el final de la Segunda Guerra Mundial que la transición del dominio formal al dominio real del capital en el área euronorteamericana puede considerarse definitivamente completada. El dominio real tiene como presupuesto 'una revolución completa (que continúa y se repite constantemente) en el modo de producción y en la productividad del trabajo y en la relación del 
embargo, ya bajo el dominio formal del capital, y por primera vez en la historia, los homosexuales se organizaron en movimiento: esto sucedió, desde la segunda mitad del siglo pasado, en Alemania, gracias a la difusión de las obras de Ulrichs ${ }^{2}$ y con la fundación del Comité científico humanitario (1897), así como, de manera diferente, en

capitalista y el trabajador' (Marx). Se basa en la producción de plusvalía, ya no absoluta, sino relativa. La 'producción por la producción - la producción como un fin en si mismo', -agrega Marx-, 'ciertamente esto ya es sumisión formal del trabajo al capital, tan pronto como en general, el fin inmediato de la producción se convierte en la producción de una plusvalía, la más grande y numerosa que sea posible, y tan pronto como en general el valor de cambio del producto se convierte en el propósito decisivo. Sin embargo, esta tendencia inmanente de la relación capitalista se realiza de modo adecuado -y se convierte en una condición necesaria (notwendige Bedidung) incluso tecnológica- sólo cuando el modo de producción específicamente capitalista se ha desarrollado y con él la sumisión real de trabajo al capital'. Con el dominio real, el capital manifiesta la tendencia a dominar la ley del valor, explotándola en su beneficio' (Camatte). En un período de dominación formal 'el capital domina al proletariado y su dominio es el dominio del capital variable. El capital se interesa en utilizar un máximo de trabajadores para lograr un máximo de plusvalía. [...]. Cuando pasamos al periodo de dominación real, el elemento esencial se convierte en capital fijo' (Camatte). Se lleva a cabo una socialización no solo de la producción, sino también del hombre mismo (ambos en relación con la devaluación): "la gran industria produce al trabajador en general (Gesamtarbeiter), que es la misma base que el hombre social del mañana' (Camatte). Después de haber sometido toda la producción, el capital también somete a los medios de circulación. Además, el dominio real implica como rasgos característicos: la autonomización del capital (cfr. Il capitale totale cit., pp. 113 sgg.); la expropiación de los capitalistas (p. 126); el pleno desarrollo de intereses y del crédito, y la producción de capital ficticio (pp. 128 y ss.); la absolutización del capital (su aspiración a la eternidad, a la inmortalidad: pp. 133 ss.); la autonomización de formas derivadas del valor (pp. 141 ss.). La ley del valor se convierte en la ley de los precios de producción.

El dominio real del capital se manifiesta como 'fascismo generalizado para todas las naciones en las que se han desarrollado las relaciones de producción capitalistas' escribe Jacques Camatte-. El Estado del Capital se presenta como garante de una distribución justa entre todos los hombres. Los reclamos ya no se presentan en nombre de un ideal político, sino de un ideal social; ya no se plantea la cuestión del poder, sino la de las estructuras y, también, en los siguientes términos: las estructuras deben reformarse para que todos puedan aprovechar los beneficios del crecimiento económico. El fascismo se resuelve con la socialdemocracia. [...]. Las diversas justificaciones de la sociedad capitalista [...] se derivan de la autonomización de las relaciones sociales y de su reificación. 'Son las crisis las que ponen fin a esta aparición de la autonomía de los diferentes elementos, en las que el proceso de producción se descompone constantemente y que se reproduce constantemente' (Storia delle teorie economiche, vol. III, p. 525).

2 KARL HEINRECH ULRICHS, Vindex e Inclusa. Cfr. JOHN LAURITSEN e DAVID THORSTAD, Il rimo movimento per $i$ diritti degli omosessuali (1864-1935), en Gay Gay: storia e coscienza omosessuale, La Salamandra, Milano 1976. 
Inglaterra y luego, en las primeras décadas de este siglo, en Holanda, Austria, los Estados Unidos de América, la Unión Soviética y otros países. No siempre ni en todas partes el movimiento homosexual asumió el carácter de una asociación que se distinguía del comité científico humanitario y su emanación internacional (la Liga Mundial para la reforma sexual), pero en muchos países, incluso sin producir organizaciones formales específicas, el movimiento homosexual real condujo a un amplio debate sobre la homosexualidad, que por primera vez involucró a un número considerable de 'personalidades' culturales y politicas y puso de manifiesto problemas y argumentos que habian sido silenciados hasta entonces de acuerdo con uno de los tabúes más severos.

La violenta persecución nazi, estalinista y fascista, perpetrada contra los homosexuales en los años treinta y durante la guerra, borró el movimiento y con él el recuerdo de esta primera afirmación homosexual internacional importante, restaurando la ideología absoluta de la Norma. Debido a esto, es solo gracias a la investigación del nuevo movimiento gay, resucitado como Frente de Liberación Gay en los Estados Unidos en 1969 y, por lo tanto, en varios otros países, que muchos de nosotros los homosexuales, especialmente aquellos nacidos en las últimas décadas, hemos sabido de la existencia de un movimiento homosexual predecesor y nos dimos cuenta de que estábamos participando, en contra de lo que pensábamos, en una segunda y no en la primera ola del movimiento de liberación. Algunas de las preguntas que nos hacemos hoy, por ejemplo, refieren a cuestiones que ya fueron abordadas en el pasado por el primer movimiento homosexual. Una de ellas refiere principalmente tanto a los homosexuales de hoy como a los de ayer: ¿por qué razones la sociedad nos margina y nos reprime con tanta fuerza?

Hemos tratado de responder esta $y$ otras preguntas con una búsqueda que comenzó desde nuestras experiencias personales: ya sea hablando, durante las reuniones generales de los grupos, de nuestra condición existencial y social como homosexuales y comparando las diferentes opiniones; ya sea dedicándonos más en profundidad al 
análisis de experiencias individuales, a través del 'trabajo' de tomar conciencia en el contexto de colectivos restringidos (grupos de autoconciencia). En resumen, comenzamos a comprender mejor quiénes somos y por qué estamos reprimidos al comunicarnos, conocernos y encontrarnos en base a nuestro deseo común, en la perspectiva de la liberación.

Además, el nuevo movimiento gay ha emprendido la investigación histórica y antropológica ya inaugurada por el primer movimiento, ayudando a arrojar luz sobre la persecución de los homosexuales a lo largo de los siglos y sobre el origen histórico de la condena anti-gay, casi siempre condenada como natural por la ideología de la primacía heterosexual. Y, si el antiguo movimiento se dedicó en gran medida a la investigación médica y psicológica, los nuevos grupos formados también se ocupan de la psiquiatría, ya que luchan contra la persecución antihomosexual perpetrada en forma de tratamiento médico y psiquiátrico. En general, el movimiento gay refuta los (pre)juicios psiquiátricos reaccionarios sobre la homosexualidad y los homosexuales revolucionarios también se oponen a la nueva moda progresista y heterosexual de la 'homosexualidad' actualmente extendida entre los antipsiquiatras.

Por otro lado, el trabajo de tomar conciencia nos ha llevado a una confrontación inmediata con los elementos de la teoría psicoanalítica inherente a la homosexualidad. De este modo, hemos descubierto en el psicoanálisis algunas nociones importantes, como el inconsciente, por ejemplo, o la represión, que, al menos por el momento, pueden integrarse en la ciencia gay. Mientras tanto, nosotros, los homosexuales, hemos llegado a una primera conclusión segura: hemos aclarado que el odio que la sociedad heterosexual alimenta hacia nosotros es causado por la represión o 'cuasi represión' del componente homoerótico del deseo en individuos heterosexuales manifiestos, que como se sabe...- aún hoy constituyen la mayoría de los seres humanos. La eliminación general de la homosexualidad, en resumen, determina el rechazo de las expresiones manifiestas del deseo gay por parte de la sociedad. Ahora se trata de descubrir qué causó esta eliminación y, 
presumiblemente, los motivos ocultos se descubren luchando contra la represión misma, levantando [battendo] ${ }^{3}$, es decir, difundiendo los placeres y el deseo de la homosexualidad. Resulta liberador que podamos y podremos entender por qué hemos sido esclavos hasta hoy, y esto es cierto para todos, para los homo y para los hetero.

Pero, si el de represión es un concepto psicoanalítico, también es cierto que, en el contexto de la cultura contemporánea, es el psicoanálisis el que afirma la universalidad del deseo homosexual. ¿Queremos citar a Freud? Hagamos un trabajo sobre el tema. Aquí está: 'La libido de todos nosotros -leemos- oscila normalmente a lo largo de la vida entre el objeto masculino y el femenino'4. ¿Por qué entonces, nos preguntaremos, si todas las personas también son homosexuales, tan pocos admiten ser homosexuales y disfrutan de su homosexualidad?

\section{Polimorfismo 'perverso': universalidad del deseo homosexual. Bisexualidad y transexualidad}

El andrógino, en efecto, era entonces una cosa sola en cuanto a forma y nombre, que participaba de uno y de otro, de lo masculino y de lo femenino, pero que ahora no es sino un nombre. PLATON 5

El psicoanálisis llega a la observación del polimorfismo 'perverso' infantil y reconoce la presencia en todos de una disposición erótica dirigida hacia personas del mismo sexo.

\footnotetext{
3 En este libro siempre usaré el término battere en el sentido gay de buscar (u ocuparse de encontrar, o 'presumir' mientras se espera) a alguien con quien hacer el amor. Si, en el lenguaje de las prostitutas y las putas, battere significa buscar clientes, para nosotros los homosexuales, en cambio, battere no significa prostitución, sino simplemente buscar a otras personas 'que están alli' (sin embargo, siempre puede suceder encontrarse con un estadounidense o un comasco que ofrece una cena en el Hilton y una corbeille de rosas baccarat). En el sentido gay, el battere italiano corresponde al draguer francés, al to cruise inglés, para el alemán... no lo sé (está aquí conmigo un maricón vienés tan ingenuo que no conoce la expresión equivalente en su lengua materna).
}

4 SIGMUND FREUD, The psychogenesis of a case of female homosexuality, "The International Journal of Psycho-analysis", 1920, vol. I, n. 2, p. 125.

${ }^{5}$ PLATONE, Simposio 189e, en Opere complete, vol. III, Laterza, Bari 1974, p. 173. 
Según Freud, el niño está 'constitucionalmente calificado' para el polimorfismo 'perverso': todas las llamadas 'perversiones' son parte de la sexualidad infantil (sadismo, masoquismo, coprofilia, exhibicionismo, voyeurismo, homosexualidad, etc.). De hecho, "la disposición a las perversiones es la disposición originaria y universal de la pulsión sexual de los seres humanos, y a partir de ella, a consecuencia de alteraciones orgánicas e inhibiciones psíquicas, se desarrolla en el curso de la maduración la conducta sexual normal'6. Entre los poderes inhibitorios que limitan la dirección de la pulsión sexual están básicamente 'las construcciones sociales de la moral y la autoridad ${ }^{7}$. La sociedad represiva y la moral dominante consideran solo la heterosexualidad 'normal' -y, en particular, la genitalidad heterosexual. La sociedad actúa de manera represiva sobre los niños, a través de la educastración, para obligarlos a eliminar las tendencias sexuales congénitas que considera 'perversas' (y, en realidad, se puede decir que incluso hoy en día son consideradas 'perversas' más o menos todos los impulsos sexuales infantiles, incluidos los heterosexuales, ya que a los niños no se les reconoce el derecho a disfrutar eróticamente). El objetivo de la educastración es la transformación del niño, que tiende a lo polimórfico y 'perverso', en un adulto heterosexual, mutilado eróticamente pero que cumple con la Norma.

La mayoría de los psicoanalistas reconocen las manifestaciones sexuales ya en los primeros meses y en los primeros años de vida y enumeran las etapas evolutivas de tendencias más o menos conscientes que se pueden resumir en el esquema: autoerotismo-homosexualidadheterosexualidad. Pero esta 'evolución' no es natural: refleja la influencia represiva del entorno socio-familiar en el niño, tampoco, por otro lado, la vida real necesariamente implica una 'superación' del autoerotismo y la 'etapa' homosexual por la heterosexualidad exclusiva del niño. El entorno en el que vivimos (en primer lugar, la familia, la célula del tejido social) es heterosexual: como tal obliga al niño, al

${ }^{6}$ FREUD, Tre saggi sulla teoria sessuale, en La vita sessuale, Boringhieri, Torino 1974, p. 131.

7 Ibid. 
hacerlo culpable, a renunciar a la satisfacción de sus propios deseos auto- y homoeróticos y lo obliga a identificarse con un modelo monosexual de tipo heterosexual mutilado. Pero no siempre tiene éxito, obviamente.

El psicoanálisis define las primeras manifestaciones de la naturaleza erótica como 'indiferenciadas' o, en cualquier caso, poco diferenciadas: en otras palabras, la elección de objeto, para el niño, se debería más a las circunstancias que al sexo (y las circunstancias, durante una jornada, sufren varios cambios). Todas las chicas también son lesbianas, y todos los chicos también son maricones.

Para aquellos que se preguntan si uno nace o se convierte en homosexual, uno debe responder que uno nace con una disponibilidad erótica muy amplia, dirigida primero hacia uno mismo y hacia la madre y luego gradualmente volviéndose hacia 'todos' los demás, independientemente de su sexo, y hacia el mundo, y ese se vuelve, debido a la educastración, heterosexual u homosexual (eliminando los impulsos homoeróticos en el primer caso, eliminando los heterosexuales en el segundo).

En este punto, sin embargo, podemos preguntarnos si es correcto hablar de la represión de las tendencias homosexuales o heterosexuales: según Georg Groddeck, por ejemplo, ningún heterosexual realmente elimina sus deseos homoeróticos por completo, sino que finge haberlos eliminado. Más que eliminada, la homosexualidad está latente en la mayoría de las personas (ya que generalmente los deseos por el otro sexo están latentes en los homosexuales). Según Freud, 'tenemos dos clases de inconciente: lo latente, aunque susceptible de conciencia, y lo reprimido, que en sí y sin más es insusceptible de conciencia'8. Correctamente, por lo tanto, deberiamos hablar sobre los deseos homosexuales latentes y otros realmente reprimidos: sin embargo, dado que no es fácil de distinguir, a veces hablaré de la homosexualidad latente y en otros casos de represión de la homosexualidad, sin establecer distinciones muy

8 FREUD, L'Io e l'Es, Boringhieri, Torino, 1976, p. 22. 
precisas $\mathrm{y}$, por lo tanto, usaré el concepto de represión en un sentido algo elástico. Por otro lado, frente a la hábil seducción de un hombre gay, no hay represión del deseo homosexual que se mantenga: los heterosexuales, tarde o temprano, están todos allí de una manera $u$ otra. Todas son reinas latentes.

De hecho, la homosexualidad latente realmente existe en todos aquellos que no son homosexuales manifiestos, como un remanente de la sexualidad infantil, polimórfica y 'perverso' y, por lo tanto, gay: residual, porque la sociedad reprime el homoerotismo, condenado precisamente a la latencia y sublimado bajo forma de sentimientos de amistad, camaradería, etc., y / o convertidos, o más bien deformados, en síndromes patológicos 9 .

En este libro, llamaré a la transexualidad la disposición erótica infantil polimórfica e 'indiferenciada', que la sociedad reprime y que, en la vida adulta, todo ser humano lleva dentro de sí mismo en el estado de latencia o confinado en los abismos del inconsciente bajo el yugo de la represión. El término 'transexualidad' me parece el más adecuado para expresar, al mismo tiempo, la pluralidad de las tendencias de Eros y el hermafroditismo original y profundo de cada individuo. ¿Pero qué quiere decir 'hermafroditismo original y profundo'?

Para el psicoanálisis, el hallazgo del polimorfismo 'perverso' infantil resulta ser complementario a la teoria de la bisexualidad originaria (y es a la luz de esta teoría que uno comprende aún mejor lo que quiero decir con transexualidad infantil y la naturaleza transexual de las profundidades). La teoria de la bisexualidad original se ha formulado, entre otros, con el objetivo de ilustrar las causas de la llamada 'inversión sexual' (homosexualidad) ${ }^{10}$. Comienza por detectar la coexistencia en el individuo de factores somáticos que pertenecen a ambos sexos: como observa Daniel Paul Schreber (que no era médico pero era una gran delirante), 'en los primeros meses de embarazo

\footnotetext{
${ }^{9}$ Cfr. el cap. III.

$10 \mathrm{El}$ término homosexualidad (del griego: igual, similar + sexualidad) fue acuñado en 1869 por el médico húngaro Benkert. Cfr. LAURITSEN-THORSTAD, Il primo movimento cit., pp. 9-22.
} 
existen los elementos de ambos sexos, y las particularidades del sexo que no se desarrollarán permanecerán, como hemos visto, por ejemplo, los pezones masculinos, como órganos rudimentarios con un menor grado de desarrollo'11. También realizó un argumento similar para el clitoris en la mujer. De observaciones similares resulta que el sexo nunca es único, y que la monosexualidad oculta una bisexualidad (un hermafroditismo). Según el psicoanálisis, todos somos seres bisexuales.

El tema fue investigado desde un punto de vista genético y endocrinológico. Gilbert Dreyfus escribe: 'Aunque el sexo genético está determinado por la constitución del espermatozoide fertilizante (por lo tanto, el padre es responsable solo del sexo genético del feto), el embrión pasa, al comienzo de su desarrollo, una fase de sexualidad aparentemente indiferenciada. Solo a partir del segundo mes de vida fetal, el bosquejo genital comienza a orientarse para llegar, a través de un largo viaje y dependiendo de si las cadenas de la primera proliferación se desarrollan o se atrofian para dar paso a las cadenas de una segunda proliferación, a la constitución de un testículo o un ovario: pero en los adultos de ambos sexos persistirán residuos del sexo opuesto, lo que atestigua el doble desarrollo masculino y femenino de las gónadas embrionarias y el sistema de doble evacuación del que inicialmente se proporciona el embrión'12.

Puede suceder que, en esta circunstancia embrionaria, existan discrepancias entre el sexo genético y el genital (entonces, el hijo de Hermes y Afrodita se confunde con el cuerpo de la ninfa Salmace): el resultado serán combinaciones de caracteres masculinos y femeninos, hermafroditismo o 'pseudohermafroditismo', estados 'intersexuales' o mejores 'casos' de transexualidad manifiesta ${ }^{13}$.

11 DANIEL PAUL SCHREBER, Memorie di un malato di nervi, Adelphi, Milano 1974, p. 73.

12 GILBERT DREYFUS, L'omosessualità vista da un medico, "Ulisse», fasc. XVIII, 1953, p. 642.

13 Ver, para más información, el libro de HARRY BENJAMIN, Il fenomeno transessuale, Astrolabio, Roma 1968. 
Sin embargo, los 'casos' de transexualidad manifiesta no siempre se determinan solo en función de las condiciones fisiológicas particulares de los sujetos. Hay muchos transexuales conscientes, por ejemplo, tan fisiológicamente masculinos como pueden ser Alain Delon, Muscolo o Enrico Berlinguer. Pero entonces, ¿qué significa ser transexuales manifiestos hoy?

En general, se llaman transexuales todos los adultos que viven conscientemente su hermafroditismo y reconocen en sí mismos, en sus propios cuerpos y mentes, la presencia del 'otro' sexo.

Actualmente, los 'casos' de transexualidad manifiesta reflejan los problemas relacionados con la contradicción entre los sexos y la represión de Eros, que es una represión de la disposición transexual universal (o polimorfo y hermafrodita) humana: los transexuales manifiestos, perseguidos por la sociedad que no admite la confusión entre los sexos, a menudo tienden a reducir su transexualidad real a la aparente monosexualidad, tratando de identificarse con el sexo histórico 'normal' opuesto a su sexo genital; así, la mujer transexual se sentirá como un hombre, eligiendo la virilidad, mientras que el hombre transexual se sentirá como una mujer, eligiendo la feminidad. Un ser humano con sexo 'no especificado' circula en las calles de la capital con mucha menos facilidad que un hombre que parece, a todos los efectos exteriores, una mujer o una mujer que se parece a un hombre. Por lo tanto, hoy, a menudo, aquellos que se conocen a sí mismos como transexuales quieren cambiar de sexo (genitales) y de hecho pueden optar por Casablanca o Copenhague, por el 'cambio de sexo' por operación, o, más frecuentemente, pueden limitarse a la identificación psicológica con el sexo 'opuesto'.

La sociedad induce a los transexuales manifiestos a sentirse monosexuales y a ocultar su hermafroditismo real. Pero, para decir la verdad, así es como la sociedad se comporta con todos: de hecho, todos somos, en nuestra profundidad, transexuales, todos hemos sido niños transexuales y nos han obligado a identificarnos con un rol monosexual específico, masculino o femenino. En el caso de los transexuales manifiestos, es decir, aquellas personas raras que no han eliminado su 
transexualidad al crecer, la coerción social produce efectos inversos con respecto a los 'normales', ya que el hombre tiende a identificarse con la mujer y la mujer con hombre.

Como veremos, la transexualidad manifiesta no implica necesariamente una propensión particular a la homosexualidad: hay varios transexuales heterosexuales. Pero entonces, por ejemplo, si son hombres y se sienten mujeres y quieren mujeres sexualmente, su heterosexualidad es, en cierta forma, homosexualidad. Lejos de ser particularmente absurda en sí misma, la transexualidad anula las categorías separadas y opuestas de sexualidad consideradas 'normales', de las cuales destaca, más bien, el carácter absurdo.

En cualquier caso, aquellos que se reconocen como transexuales, hoy, manifiestan totalmente (bisexualidad)-transexualidad latente. Su condición los acerca o los lleva a la conciencia potencialmente revolucionaria del hecho de que todo ser humano, embriológicamente bisexual, retiene en sí mismo durante toda la vida, desde el punto de vista biológico y psicológico, la presencia del otro sexo. Creo que la superación de las categorías actuales separadas y antitéticas de la sexualidad será transexual y que en la transexualidad se comprenderá la sintesis de las expresiones del Eros liberado. Volveré más tarde, a menudo, sobre estos temas ${ }^{14}$.

Por el momento, limitémonos a observar que 'nuestra bisexualidad hormonal está ampliamente demostrada'15 y que la determinación del sexo ‘definitivo' y manifiesto al nacer solo significa de forma general su 'predominio' en el individuo, pero no elimina en absoluto la presencia sexual 'opuesta'.

Desde el punto de vista filogenético, la concepción que se deriva de la observación de estos datos biológicos, anatómicos y endocrinológicos 'es

\footnotetext{
${ }^{14}$ Este libro es sobre todo informativo. Por lo tanto, no me referiré al 'punto de vista' esotérico del andrógino (o ginandro), también porque, en la gran ruta, solo he dado los primeros pasos -y de mis experiencias podria hablar, si queremos, en una novela, pero ciertamente no, todavia, en forma de ensayo (dada mi ignorancia). En cualquier caso, en el capítulo $\mathrm{V}$ abordaré la cuestión transexual en relación con la alucinación considerada 'esquizofrénica'.
}

15 DREYFUS, L'omosessualità, cit., p. 643. 
la de una disposición originariamente bisexual que, en el curso del desarrollo, se va alterando hasta llegar a la monosexualidad con mínimos restos del sexo atrofiado' (Freud) ${ }^{16}$.

Muy importante es la transposición de esta concepción al campo psíquico, lo que lleva a interpretar la homosexualidad 'como expresión de un hermafroditismo psíquico' (Freud) ${ }^{17}$. Pero, si la teoría del hermafroditismo psíquico contribuye a demostrar, para el psicoanálisis, la posibilidad de la llamada 'inversión sexual', por otro lado, invierte la fijación de la pulsión sexual de personas consideradas 'normales' en 'objetos' del sexo 'opuesto': 'en el sentido del psicoanálisis, entonces, ni siquiera el interés sexual exclusivo del hombre por la mujer es algo obvio, sino un problema que requiere esclarecimiento, respecto del cual cabe suponer una atracción en el fondo de carácter quimico' (Freud) ${ }^{18}$. Según Groddeck, es más difícil explicar por qué se perciben los impulsos heterosexuales que comprender por qué existen en todos las tendencias homosexuales, que, en su opinión, derivan 'como una consecuencia necesaria del amor propio'19.

¿Existe, por lo tanto, una estrecha relación entre el hermafroditismo psicofísico y la homosexualidad? Sí, porque la homosexualidad es congénita $\mathrm{y}$, por lo tanto, una expresión del polimorfismo típico de nuestro ser transexual profundo, hermafrodita. Del mismo modo, las tendencias eróticas hacia el sexo 'opuesto' también forman parte de nuestro polimorfismo erótico y, por lo tanto, son una expresión de hermafroditismo profundo. Tanto el deseo homosexual como el deseo por el otro sexo están relacionados con la naturaleza transexual de lo profundo.

Esto es tanto más evidente en cuanto la heterosexualidad misma a menudo se acompaña de aquello que los médicos, con su lenguaje represivo, definen como 'trastornos morfológicos y hormonales'. Todavía

\footnotetext{
16 FREUD, Tre saggi, cit., p. 40.

17 Ibid.

18 Ibid., p. 44 (nota agregada en 1914).

19 GEORG GRODDECK, Il libro dell'Es, Adelphi, Milano, 1971, p. 293.
} 
tomando prestada la odiosa terminología médica, observaremos cómo, muy comúnmente, los hombres heterosexuales son 'hipoviriles' y 'afeminados'. La característica hormonal que acompaña a estas formas de 'hipovirilismo' 'es el colapso de la relación andrógenos/estrógenos, luego de la disminución del numerador y la elevación del denominador'20. La heterosexualidad, por lo tanto, a menudo va acompañada de expresiones obvias de hermafroditismo físico.

Por otro lado, a pesar del lugar común que identifica al maricón con el 'afeminado', un alto porcentaje de homosexuales manifiestos no presentan formas particulares de 'hipovirilismo' y 'afeminamiento'. En resumen, no existe una relación general de proporcionalidad directa entre el 'hipovirilismo' y la homosexualidad masculina, ni entre el 'hipofeminismo' (!) y la homosexualidad femenina. Mujeres 'masculinas' pueden ser decididamente heterosexuales, y mujeres muy 'femeninas' gay.

Con respecto a la supuesta relación necesariamente existente entre el 'afeminamiento mental' y la homosexualidad masculina y entre la 'masculinidad psicológica' y la homosexualidad femenina, Freud, señala que la bibliografia sobre la homosexualidad no suele distinguir con nitidez suficiente el problema de la elección de objeto, por un lado, y el del carácter y la actitud sexuales, por el otro, como si la decisión sobre uno de esos puntos se enlazara necesariamente con la decisión sobre el otro. Pero la experiencia muestra lo contrario: Un hombre con cualidades predominantemente viriles, y que exhiba también el tipo masculino de vida amorosa, puede, con todo eso, ser un invertido con relación al objeto, amar sólo a hombres, no a mujeres. Un hombre en cuyo carácter prevalezcan de manera llamativa las cualidades femeninas, y aun que se porte en el amor como una mujer, en virtud de esa actitud femenina debería estar destinado al varón como objeto de amor; no obstante, muy a pesar de eso, puede ser heterosexual y no mostrar hacia el objeto una inversión mayor que una persona normal media. Lo mismo vale para las mujeres; tampoco en ellas carácter

20 DREYFUS, L'omosessualità, cit., p. 644. 
sexual y elección de objeto coinciden en una relación fija. Por tanto, el misterio de la homosexualidad en modo alguno es tan simple como se propende a imaginarlo en el uso popular: Un alma femenina, forzada por eso a amar al varón, instalada para desdicha en un cuerpo masculino; o un alma viril, atraída irresistiblemente por la mujer, desterrada para su desgracia a un cuerpo femenino'21. En pocas palabras: más allá de cualquier lugar común, un semental puede ser un maricón, un mujeriego estilizado y refinado, una doncella puede ser una lesbiana, una institutriz alemana robusta irremediablemente heterosexual. Este es el mundo.

Para concluir, diremos que si ni la homosexualidad ni la heterosexualidad manifiesta corresponden necesariamente a características psíquicas, somáticas y hormonales específicas, tanto el deseo gay como el deseo del otro sexo son expresiones de nuestro ser transexual profundo, que tiende hacia lo polimórfico, forzado por la represión para adaptarse a una monosexualidad que la mutila. Pero la sociedad represiva considera solo un tipo 'normal' de monosexualidad, la heterosexual, y establece la educastración para determinar exclusivamente la heterosexualidad. Por lo tanto, la Norma es heterosexual.

\section{Afirmación de la heterosexualidad y malentendido de la mujer en si}

La teoría de la bisexualidad fue apoyada originalmente por la psiquiatría como la base de la etiología de la 'inversión sexual'. Sin embargo, hemos visto cómo el psicoanálisis, que lo adopta, pronto nos lleva a cuestionar las causas de la fijación del deseo de personas consideradas sexualmente 'normales' por la sociedad en 'objetos' del sexo opuesto. La pregunta que surge es la siguiente: ¿por qué, en el curso del desarrollo ontogenético, el individuo pasa de la disposición erótica 'indiferenciada' dirigida a ambos sexos propia de la libido infantil a una fijación (de tipo hetero $u$ homosexual) en un único sexo como

\footnotetext{
${ }^{21}$ FREUD, The psychogenesis, cit., p. 147.
} 
'objeto' de deseo? "La question alors est de savoir comment on opte pour une unisexualité" (Jacques Camatte).

La respuesta inmediata es que esto sucede por la acción de la educastración, o por influencia en el individuo de la sociedad, del mundo 'externo', en el que existe una Norma monosexual, cuya represión se transmite de generación en generación. Sin embargo, la Norma monosexual es, como ya he dicho, decididamente heterosexual, y la abstracción que tiende a afirmarla universalmente significa que, entre la mayoría de las personas, la monosexualidad se presenta actualmente como heterosexualidad. La Norma se basa en la mutilación de Eros y, en particular, en la condena de la homosexualidad. Por lo tanto, es evidente que, sólo cuando se entiende por qué los impulsos homoeróticos son reprimidos en la mayoría de los individuos, por la sociedad en su conjunto, será posible comprender qué determina la afirmación exclusiva o altamente predominante del deseo heterosexual entre la mayoría. Por otro lado, el problema de la represión de la homosexualidad está estrechamente relacionado, hoy, también con la afirmación del deseo homoerótico exclusivo o prevalente entre nosotras, maricas y lesbianas: dado que, históricamente, es la represión del homoerotismo lo que, en gran medida, contribuye a caracterizar las expresiones actuales de homosexualidad manifiesta.

Sabemos cómo, al crecer, el niño se ve obligado a desarrollar sobre todo aquellas tendencias que son una manifestación de su 'masculinidad' psicológica: quien lo obliga es la sociedad, en primer lugar a través de la familia, así como a través de la educación y la familia, la sociedad obliga a la niña a desarrollar aquellos aspectos de su personalidad que son una expresión de la 'feminidad' psicológica. De esta manera, la educastración tiende sobre todo a negar el hermafroditismo psíquico y biológico presente en todos, para hacer de la niña una mujer y del niño un hombre según los modelos sexuales opuestos de polaridad heterosexual. La 'masculinidad' y la 'feminidad' psicológica, expresadas respectivamente y por separado por la niña y el niño como resultado de la educación (que es sobre todo una relación de subordinación hacia los padres $\mathrm{y}$, en general, hacia los adultos), no 
hacen más que reflejar las formas históricas contingentes y mutiladas de virilidad y feminidad que la sociedad absolutiza y que se basan en la sujeción-represión de las mujeres, en la alienación del ser humano mismo y en la negación de la comunidad humana.

La sociedad y la familia inducen al niño a tomar al padre como modelo de su vida; se ve obligado a aspirar a ser como él en todo y para todo, pero esto no puede suceder a menos que sea a costa de la afirmación completa de sí mismo: de hecho, esto no tiene lugar excepto a través de una mutilación. El padre, de hecho, ya ha sido educado, y el hijo no puede identificarse realmente con su padre a menos que sea mutilado. Gradualmente, a través de esta identificación, el niño, como su padre, proyecta sobre la madre y otras mujeres los elementos 'femeninos' que existen en su propia psique; elementos que está obligado a no admitir en su conciencia, obligado a avergonzarse de ello, a pesar de que lo atraen profundamente como un componente fundamental de su ser. De esto deriva una de las mayores calamidades que han afectado a la especie: la negativa del hombre a reconocer en sí mismo a la 'mujer', la transexualidad.

Para decirlo en palabras de Jung, el padre se convierte para el hijo en el modelo de la Persona: 'la Persona es un sistema complicado de relaciones entre la conciencia individual y la sociedad, un tipo de máscara que sirve, por un lado, para causar una cierta impresión en los demás, por el otro, ocultar la verdadera naturaleza del individuo 22 .

A través de la identificación con el padre, la sociedad obliga al niño a construir una personalidad artificial, de acuerdo con la Norma vigente en el mundo 'externo' y que, al mismo tiempo, actúa como defensa contra los peligros del mundo 'externo', los escollos del escenario de las personas.

Sin embargo, "la construcción de una Persona conveniente para el colectivo es una grave concesión al mundo externo, un verdadero sacrificio personal, que obliga al Yo a identificarse incluso con la Persona, tanto que hay personas que creen seriamente en ser eso que

22 CARL. G. JUNG, L'Io e l'inconscio, Boringhieri, Torino 1973, p. 109. 
representan' (Jung) 23. El niño no puede identificarse con el padre, es decir, no puede construir una personalidad similar a la de su padre si no se sacrifica a si mismo, su transexualidad y en particular su 'feminidad'. 'La eliminación de los rasgos y tendencias femeninas conduce naturalmente a la acumulación de estas afirmaciones en el inconsciente' (Jung).

Una represión drástica de la homosexualidad también tiene lugar durante la primera infancia: el padre se (re)presenta a sí mismo como una persona decididamente heterosexual y rechaza el contacto erótico abierto con su hijo (que en cambio desea 'indiferenciadamente' y, por lo tanto, también quiere a su padre), así como a otros hombres adultos, en virtud de tabú anti-pedofilia, rechazando las relaciones sexuales con el niño. Del mismo modo, la madre y las mujeres adultas evitan las relaciones sexuales con el niño (aunque, en general, existe una mayor intimidad erótica entre madre e hijas que entre padre e hijos). Además, se reprimen las relaciones sexuales mismas $\mathrm{y}$, en particular, las homosexuales entre niños.

El tabú anti-homosexual, que se aplica muy severamente entre los adultos, pronto induce al niño a aprender que la homosexualidad está prohibida, que ni siquiera se puede hablar de eso o que en cualquier caso solo se puede hablar en un sentido despectivo, y que uno debe estar avergonzado de los propios impulsos homosexuales, ya que uno debe estar avergonzado de su 'feminidad'. A los ojos del niño, la homosexualidad se relaciona inmediatamente con las tendencias 'femeninas': de hecho, la atracción sexual por el sexo masculino es hoy un impulso culturalmente combinado con la feminidad -y esta cultura influye negativamente en el niño desde su nacimiento.

La represión de la homosexualidad resulta ser tan dura que obliga al niño a olvidar su deseo gay, es decir, a eliminarlo (lo que desafortunadamente casi siempre ocurre).

La identificación con el padre se basa en gran medida en la eliminación del deseo erótico por el padre. La identificación constituye 
una especie de introyección del padre que, como tal, alivia o facilita su renuncia como un 'objeto' sexual. Según Freud, uno puede pensar que 'el carácter del yo es una sedimentación de las investiduras de objeto resignadas, contiene la historia de estas elecciones de objeto'24. Por otro lado, 'Cuando el yo cobra los rasgos del objeto, por así decir se impone él mismo al ello como objeto de amor, busca repararle su pérdida diciéndole: "Mira, puedes amarme también a mí; soy tan parecido al objeto...n'25.

En el caso de la renuncia del padre como un 'objeto' amoroso y de la identificación con él por parte del niño, se produce una transformación de la libido homosexual en una libido narcisista: esta transformación, determinada no solo por el tabú del incesto sino por la condena de la homosexualidad, está en la base del Yo 'normal', heterosexual y antihomosexual de su Egoísmo. El hombre heterosexual, eliminando el deseo gay, introyecta los 'objetos' homosexuales y se coloca a sí mismo como el único 'objeto homosexual', transformando la homosexualidad en autoerotismo e imponiendo su autoerotismo a las mujeres en relaciones heterosexuales. Pero este autoerotismo está alienado, ya que se basa en la renuncia del padre como un 'objeto' sexual y, más general, en la eliminación del deseo gay, en el sacrificio de los componentes 'femeninos' combinados con la homosexualidad e incompatibles con la identificación con el padre y con la Norma. Es este autoerotismo masculino enajenado el que las mujeres rechazan: implica tal concentración de deseo para el hombre en el hombre para hacer del hombre una virilidad condensada ciega y egoísta que pretende imponerse a las mujeres, quienes encarnan esa feminidad que él negó para sí mismo, avergonzado de ello. Los hombres heterosexuales ven en las mujeres esa parte de sí mismas que se esfuerzan por ocultar y eliminar de la infancia: es por eso que las 'aman' de manera notoria.

El ego masculino 'normal' -resumiendo- está determinado en gran medida por una serie de elecciones de objetos homosexuales

\footnotetext{
${ }^{24}$ FREUD, L'Io e l'Es, cit., p. 44.

25 Ibid., p. 45.
} 
abandonados, transformados en libido narcisista, a la cual se le indican metas de tipo heterosexual. En los 'objetos' heterosexuales, el hombre proyecta su 'feminidad', previamente eliminada. La mujer, por lo tanto, está doblemente sujeta al hombre: dado que el hombre le impone su virilidad (como una condensación del deseo homosexual enajenado) y su propia 'feminidad'. La mujer no es reconocida como un ser autónomo, pero históricamente está calificada en relación con el hombre, sobre la base de una heteronomía completa: y la heterosexualidad, como se presenta actualmente, se basa en la heteronomía de la mujer y tiende a perpetuarla. La Norma, por lo tanto, apoyada por la sociedad represiva en la que existe la supremacía masculina, solo puede ser heterosexual.

Como dice una mujer ${ }^{26}$, 'la feminidad es un disfraz, es un hombre que proyecta una idea de la mujer después de haberla censurado, asfixiado, marginado y puesto en un gineceo. Ya no tiene derecho al habla, ni a su cuerpo, ni a su disfrute [...]. Se apodera de la representación, de un sistema de representación, de una escena histórica que quiere programar; la feminidad será así, un hombre disfrazado, después de lo cual una mujer puede regresar por un efecto de duplicación de este disfraz e imita al pervertido que imitó la feminidad. Mujer, todavía no la hay. Es dificil decirlo, pero cada mujer puede escucharlo fácilmente, comprenderlo. Comenzando desde el momento en que empieza a hablar, hasta existir, se enfrenta a problemas que son completamente masculinos, y esto es lo que la pone en peligro de muerte: si no los toma prestados, no existe y si los toma a préstamo muere por dentro. Es en este límite que estamos y que lucharemos. Históricamente, las mujeres aún no existen y el propósito del movimiento es hacerlas aparecer, históricamente -como un lugar diferenciado. Es la alteridad, una mujer'.

Pero volvamos al bebé. Precisamente porque fueron reprimidos, él proyecta los rasgos psíquicos 'femeninos', que se transfieren a una persona femenina, generalmente la madre. Se establece una especie de

${ }^{26}$ Cfr. Assenti e dappertutto, "L’Erba Voglio", n. 26, giugno-luglio 1976, p. 7. 
complicidad 'homosexual' intima entre madre e hijo: la madre es la única que puede entender, intuir las necesidades de la 'vida femenina' de su propio hijo y que puede satisfacerlas parcialmente (entre estas, las cuestiones de dulzura, ternura, protección, ser amado, siempre que lo necesite). Obligado a reprimir su componente 'femenino' para identificarse con su padre, el niño también está obligado a reprimir su propensión al don, la ternura, la sensualidad, la maternidad ${ }^{27}$ : esto en particular lo lleva a requerir ternura, afecto, sensualidad, la donación completa, maternidad de la madre. Así es como se induce al hombre a girar a la mujer desde una edad temprana.

Por su parte, la madre 'dirige sobre el niño sentimientos que brotan de su vida sexual, lo acaricia, lo besa y lo mece, y claramente lo toma como sustituto de un objeto sexual de pleno derecho' (Freud) ${ }^{28}$. Sin embargo, para la madre, la pedofilia está prohibida, al igual que el incesto, por lo que su relación erótica con su hijo se produce indirectamente, enajenada y el niño realmente la representa como un sustituto de un 'objeto' sexual en plena ley. Esta primera relación sexual reprimida deja un rastro ominoso en la vida (erótica) de cada uno.

'Por lo tanto, hay una doble serie de contradicciones en la relación madre-hijo en la sociedad burguesa' -observa Myriam Cristallo. 'La primera es que la enseñanza amorosa-sexual es impartida, dentro del entorno familiar, por la madre, [...] con la excepción de una relación dialéctica más amplia con los demás. La segunda, estrechamente entrelazada con la primera, es que la enseñanza amorosa transmitida ya está viciada en sí misma, ya que proviene de las experiencias concretas de los padres, llevadas a cabo en el terreno enajenado del mercado amoroso'29.

Sin embargo, es precisamente a través de la relación con la madre que el niño se hace una primera idea de la mujer. Además del contacto

27 Que las personas tienen deseos de maternidad es algo probado y descrito por el psicoanálisis. Cfr., por ejemplo, GRODDECK, Il libro dell'Es cit.

28 FREUD, Tre saggi, cit., p. 124.

29 MYRIAM CRISTALLO, Ma l'amor di madre resta santo, en La politica del corpo, Savelli, Roma, 1976, p. 194. 
directo con la madre, la proyección progresiva sobre ella y las otras mujeres del componente psíquico 'femenino' del niño y la imagen hereditaria colectiva de la mujer que cada hombre lleva dentro de sí, verdadera y propia, contribuyen a la formación de esta idea. Depósito propio de todas las experiencias que la humanidad que nos precedió ha vivido hacia las mujeres y en particular de su represión.

Jung dio el nombre de Anima a la imago de la mujer constituido por la acumulación en el inconsciente del hombre de los rasgos y tendencias 'femeninas' eliminadas y por la presencia en el inconsciente de una imagen hereditaria colectiva de la mujer. El Anima, por lo tanto, termina definiendo el elemento 'femenino' presente en el hombre; mientras que el Animus sería el equivalente 'masculino' de la mujer. Pero, como dice el propio Jung, 'si no es una tarea fácil explicar qué se entiende por Anima, las dificultades se acumulan hasta a la imposibilidad de exhibir la psicología del Animus'30.

En cualquier caso, según Jung, es precisamente la proyección del Anima y del Animus que orienta sexualmente al niño hacia la madre y la niña hacia el padre y empuja al hombre, en la vida adulta, a la búsqueda afectiva y sexual de la mujer y a la mujer hacia el hombre. Por lo tanto, la heterosexualidad se basaría en una red de proyecciones.

'En su elección amorosa, el hombre a menudo sufre la tentación de conquistar a esa mujer que responde mejor al carácter particular de su feminidad inconsciente; una mujer, por lo tanto, que puede aceptar fácilmente la proyección de su alma' (Jung) ${ }^{31}$.

La heterosexualidad se basa en la proyección del otro sexo latente en nosotros sobre personas del sexo 'opuesto'. Está determinado por la represión de la transexualidad, es decir, del hermafrodismo psíquico original y de las llamadas tendencias 'perversas', en particular la homosexualidad.

El niño desea 'indiferenciadamente' hasta que se ve obligado a identificarse con su padre, eliminando -como ya he dicho- los impulsos

\footnotetext{
30 JUNG, L'To e l'inconscio cit., p. 125.

31 Ibid., p.105.
} 
homoeróticos y adaptándose a un modelo heterosexual. La heterosexualidad masculina, como se presenta actualmente, se basa en la eliminación de la 'feminidad' en el hombre y en la renuncia al deseo gay y, como tal, representa una forma de sexualidad enajenada, ya que se basa en la alienación del ser humano por sí mismo. A medida que ocurre, la heterosexualidad masculina es abnegación y, por lo tanto, un malentendido del otro: dado que, de hecho, al proyectar su 'feminidad' sobre la mujer, el hombre ya no reconoce su 'feminidad' ni reconoce a la mujer. El deseo heterosexual exclusivo es una aspiración a la totalidad a través de la desaprobación de la mujer en sí misma (en sí misma: es decir de la mujer como realmente es; y de la mujer en sí misma: es decir, de la 'mujer' que está oculta en cada hombre).

La liberación de Eros y la realización del comunismo pasan necesariamente y con alegría por la (re)conquista de la transexualidad y la superación de la heterosexualidad como se presenta hoy. La lucha por la (re)conquista de la vida es también y sobre todo una lucha por la liberación del deseo homoerótico. El movimiento gay lucha por la negación de la negación de la homosexualidad: para que la propagación del homoerotismo cambie cualitativamente la existencia y la transforme de supervivencia en vida. Refiriéndose al ensayo final de la Gran Encyclopédie des Homosexualités ${ }^{32}$, Luciano Parinetto afirma que, 'en caso de aceptar la bipolaridad fundamental masculino-femenina del sexo humano, y si, al mismo tiempo, se determina la eliminación capitalista y edípica de lo femenino en lo masculino, (ya que no se elimina lo que atrae demasiado) debe decirse de los normales: eres homosexual'. 'La protesta homosexual y feminista', agrega Parinetto, 'si, como el ateísmo respecto a Dios, no quiere ser una posición por negación de ese capitalismo que lo ha hecho emerger a través de la marginación, si no quiere confirmar sus propios roles sexuales a través de la negación de los mismos, en lo que podría fundarse, debe

\footnotetext{
32 El número monográfico de 'Recherches' la Grande Encyclopédie des Homosexualités, editado por un equipo editorial de G. Deleuze, M. Foucault, Marie France, J. Genet, F. Guattari, G. Hocquenghem, JJ Lebel, JP Sartre etc., y publicado en París en Marzo de 1973, fue secuestrado por la policía el día de su lanzamiento. Cfr. a este respecto el artículo Paris-Fhar, «Fuori!», N. 10, junio-julio de 1973.
} 
presentarse como una introducción a la transexualidad, es decir, una persona totalmente distinta, tanto en lo que se refiere a la llamada normalidad como a su oposición dialéctica'33.

Parinetto tiene razón por supuesto: pero me gustaría recordar que el logro de la transexualidad necesariamente pasa por el movimiento de las mujeres y la liberación completa del homoerotismo, así como de los otros componentes del polimorfismo erótico humano; el ideal utópico de la transexualidad, si quiere ser 'una utopia concreta', no debe distanciarnos o distraernos de la dialéctica concreta actualmente en curso entre los sexos y entre las diferentes tendencias sexuales (sobre todo la heterosexualidad y la homosexualidad). Solo la lucha de quienes son los sujetos históricos de la antítesis fundamental de la norma heterosexual masculina puede conducirnos a superar la oposición actual entre sexo y sexo y entre la genitalidad homosexual y heterosexual u otras llamadas 'perversiones'. Si la transexualidad es el verdadero telos, solo se puede lograr cuando las mujeres hayan derrotado al 'poder' masculino basado en la polaridad de los sexos y entonces los homosexuales habrán abolido la Norma que propaga la homosexualidad universalmente. Además, dada la función extremadamente importante de la prolongación del capitalismo de la subordinación femenina y de la sublimación de las tendencias de Eros definidas como 'perversas' en el trabajo, la (re)conquista de la transexualidad tendrá lugar con la caída del capitalismo y con el rechazo del trabajo enajenado y alienante: la lucha de los homosexuales y las mujeres es (fundamentalmente) la revolución comunista ${ }^{34}$.

Y, si la transexualidad es el telos de la lucha por la liberación de Eros, es telos precisamente como un fin interno, futuro-pasado-presente en el inconsciente, en el poder del modo de ser reprimido y del ser-endevenir en lo que hoy comienza a afirmarse contra el capital y su Norma: quién tiene un Anima para entender, o un Animus, que entienda.

33 LUCIANO PARINETTO, L'utopia del diavolo: egualitarismo e transessualità, "Utopia", dicembre 1973.

${ }^{34}$ Abordaré estos temas importantes más adelante. Cfr. cap. VI, par. 4. 


\section{Crítica del concepto de bisexualidad. 'La neurosis es, por así decirlo, el negativo de la perversión'}

La teoría de la bisexualidad original y profunda, o 'ambisexualidad' (Ferenczi), no aclara las causas de la llamada 'inversión sexual', lo que además justifica: según Otto Weininger, autor de Sexo y carácter (1903) y entusiasta defensor de la teoría de la bisexualidad, que la homosexualidad no es ni vicio ni contra-natura, ya que cada hombre, al ser también una mujer, puede desear a otro hombre (que también es una mujer), así como cada mujer, siendo al mismo tiempo un hombre, puede bien desear otra mujer (que también es un hombre) como complemento de sí. Pero esta justificación de la homosexualidad no es necesaria (de hecho, está completamente inserta en la perspectiva sustancialmente reaccionaria de la tolerancia): Weininger no hace nada más que adaptar el esquema bipolar de la heterosexualidad al homoerotismo. La homosexualidad se explica recurriendo a categorías heterosexuales. Prefiero creer que la homosexualidad abarca, entre sus secretos, la posibilidad de comprender el hermafrodismo psíquicobiológico no tanto como bi-sexual, sino como erótico en un nuevo (e incluso remoto) sentido poli-sexual, trans-sexual. Las categorias heterosexuales se basan en la censura del hermafrodismo profundo, en la sumisión del cuerpo a las directivas neuróticas de la mente censurada, en la visión ego-ísta del mundo-vital determinada por la represión de las mujeres y del Eros, por la moral sexual coercitiva, por la negación de la comunidad humana, desde la atomización individualista. Es inútil establecer desde el fondo de nuestra relación enajenada las categorias bi-sexual y hetero-sexual sobre la superioridad de lo latente y lo reprimido: es inútil descender desde abajo, a menos que estemos satisfechos con el malentendido del alcance de lo reprimido que nos une al status quo; más bien, los revolucionarios homosexuales queremos elevarnos, liberarnos concretamente a la transexualidad. Por el momento me gustaría subrayar nuevamente cómo la misma teoría psiquiátrica, psicoanalítica, hetero-sexual de la bi-sexualidad revela la contingencia histórica del concepto de 'normalidad' erótica. Sin 
embargo, el psicoanálisis nunca ha dejado de investigar en torno a la 'desviación homosexual' -el tabú antigay encadena el psicoanálisis al grupo fuertemente pre-judicial de un punto de vista externo de la homosexualidad- en lugar de cuestionar las manifestaciones eróticas consideradas 'normales' y su absolutización ideológica. En otras palabras, el psicoanálisis no ha investigado a fondo las causas de la inversión heterosexual, porque la primacía heterosexual está demasiado cerca de su corazón (al igual que el concepto de inversión, hacer un uso adecuado implicaría descartar el uso propio). En este caso, como en muchos otros, el psicoanálisis se revela como un servidor demasiado fiel de la ideología capitalista y no se atreve a llevar sus descubrimientos al fondo, extrayendo de él las consecuencias teóricas 'extremas' (consecuencias que a veces toca, pero evitando enfocar en ellas una atención crítica completa). Así, habiendo observado la reducción de la 'bisexualidad' original a la monosexualidad heterosexual, Freud obviamente no sueña con clasificar la heterosexualidad entre las 'aberraciones': esto implicaría la eliminación de la noción misma de 'aberración'; por el contrario, recurre al estudio de la homosexualidad como prototipo de 'perversión', perjudicando así el análisis desde el principio. De hecho, en mi opinión, el concepto de ‘aberración' debería ser reemplazado por el de mutilación: de hecho, todas las formas actuales de sexualidad, precisamente porque están separadas, representan mutilaciones con respecto a la posible explicación polimórfica del Eros. Si es cierto que Freud describe el homoerotismo como un prototipo de 'perversión', también es cierto que, para ser precisos, solo el coito genital heterosexual no configura en sí mismo, según él, una 'desviación': incluso la felatio heterosexual es clasificada Freud entre las 'desviaciones relativas a la meta sexual' y constituye rigurosamente un acto 'perverso'; esto, a pesar del hecho de que él mismo afirma que 'en ninguna persona sana faltará algún complemento de la meta sexual normal que podría llamarse perverso'35. De hecho, las actividades sexuales se consideran 'normales' o 'perversas' solo sobre la

35 FREUD, Tre saggi cit., p. 59. 
base de parámetros de juicios relativos, inherentes a la época histórica. $\mathrm{Y}$, como veremos, también existe una causa económica detrás de la represión del Eros y la clasificación de los actos y tendencias sexuales entre las 'aberraciones'. Marx adopta la hipótesis de Niebuhr, según la cual todos los legisladores antiguos $\mathrm{y}$, en primer lugar, Moisés, fundaron el éxito de sus prescripciones en materia de virtud, justicia y buena moral, en la propiedad de la tierra, o al menos en la posesión de la tierra garantizada hereditariamente a tantos ciudadanos como sea posible'36. Desde un punto de vista más general, Freud afirma: 'de lo que llamamos perversiones sexuales, esas trasgresiones de la función sexual tanto en el ámbito del cuerpo cuanto en el del objeto sexual. Ya la imprecisión de los límites de lo que ha de llamarse vida sexual normal en diferentes razas y en épocas diversas debería calmar a los que dan pruebas de tanto celo. Tampoco deberíamos olvidar que la más despreciable, para nosotros, de esas perversiones, el amor sexual entre hombres, en un pueblo que tanto nos aventajaba en cultura como fue el de los griegos no sólo era tolerada sino que se le atribuían importantes funciones sociales'37. A pesar de esto en otras declaraciones similares, Freud no se pregunta qué motivaciones específicas han llevado a la civilización occidental, a lo largo de los siglos, a transformar tan radicalmente su actitud hacia la homosexualidad; es suficiente para él que el amor sensual del hombre por el hombre sea juzgado abominable por sus contemporáneos para etiquetarlo como 'perverso'. Sin embargo -dado que estamos hablando de Freud-vale la pena señalar que nunca consideró la homosexualidad patológica en sí misma. Pero el psicoanálisis enseña todavía algo más. Muestra que los síntomas en modo alguno nacen únicamente a expensas de la pulsión sexual llamada normal (no, al menos, de manera exclusiva o predominante), sino que constituyen la expresión convertida [konvertiert] de pulsiones que se designarian perversas (en el sentido más lato) si pudieran

\footnotetext{
36 KARL MARX, Lineamenti fondamentali della critica dell'economia politica, La Nuova Italia, Firenze, 1971, vol. II, p. 101.

37 FREUD, Fragment d'une analyse d'histérie (Dora), en Cinq Psychanalyses, Presses Universitaires de France, Paris 1954, p. 35.
} 
exteriorizarse directamente, sin difracción por la conciencia, en designios de la fantasia y en acciones. Por tanto, los sintomas se forman en parte a expensas de una sexualidad anormal; la neurosis es, por así decir, el negativo de la perversión'38. Para Freud, la homosexualidad manifiesta, como otras 'perversiones', no es patológica en sí misma: por el contrario, la psiconeurosis deriva (en parte) precisamente de la conversión de la llamada sexualidad 'anormal' en sindromes patológicos. La neurosis que afecta a toda la humanidad está causada sobre todo por la represión del Eros, de la mutilación del Eros que se reduce a la monosexualidad (casi siempre heterosexual). La neurosis de nosotras las maricas o de las lesbianas (y hoy podemos hablar de la neurosis de los homosexuales manifiestos, ya que es reaccionario distinguir entre neuróticos y 'sanos', ya que todos somos, heterosexuales $u$ homosexuales, más o menos, neuróticos) no depende de nuestra homosexualidad, pero podría ser causada por la traducción en términos patológicos del componente heterosexual y las consideradas tendencias 'perversas' que, a diferencia de la homosexualidad, generalmente hemos eliminado o 'casi eliminado', en diferentes grados de uno u otro caso. Sin embargo, es evidente que la neurosis que nos afecta a los homosexuales manifiestos depende también $y$, sobre todo, de la persecución social que nos vemos obligados a soportar precisamente porque somos gays. En otras palabras, es la psiconeurosis de lo 'normal' (fundada en gran parte en la conversión patológica de la homosexualidad y de las otras 'perversiones' reprimidas), lo que condena las expresiones manifiestas del homoerotismo, para provocar en gran medida la neurosis de los homosexuales: es la psiconeurosis que se basa en la represión y la eliminación del deseo homosexual que causa principalmente la psiconeurosis de los homosexuales manifiestos. No el homoerotismo, por lo tanto, pero sí persecución del homoerotismo es patológica y patógena.

\section{Psico-nazis}

38 ID., Tre saggi cit., p. 63. 
Es cierto que la opinión de Freud, según la cual la homosexualidad sería una 'perversión' y no un síndrome patológico, no es compartida por todos los psicoanalistas y psiquiatras. Esto ocurre en el contexto de la eliminación general realizada generalmente por las escuelas psicoanaliticas con respecto a los aspectos más disruptivos del pensamiento freudiano (y esta represión, en particular con respecto a la homosexualidad, involucra al propio Reich).

Sandor Ferenczi, por ejemplo, se distanció claramente del pensamiento freudiano sobre el homoerotismo. En 1909 definió la homosexualidad como una psiconeurosis y también declaró que no creía en la homosexualidad congénita ${ }^{39}$. En octubre de 1911, en cambio, durante una conferencia celebrada en el III Congreso de la Asociación Internacional de Psicoanálisis en Weimar, Ferenczi argumenta una distinción entre el homoerotismo del sujeto y el homoerotismo del objeto: 'Un hombre que se siente mujer en sus relaciones con los hombres se invierten con respecto a su propio Yo (homoeróticos por inversión del sujeto o, más simplemente, homoerotismo de sujeto), y se sienten una mujer no solo durante las relaciones sexuales, sino en todas las reacciones de su existencia'40. Este tipo de homosexualidad constituiria (observe la apresurada simplicidad de la definición de Ferenczi) una 'etapa intermedia, [...] por lo tanto, una anomalía pura del desarrollo'.

En contraste con la figura del homosexual pasivo, 'afectado' por el 'homoerotismo de sujeto', Ferenczi describe el 'verdadero homosexual activo', que 'se siente en todo y para todo un hombre, es muy a menudo enérgico [...] y no tiene nada afeminado, ni psíquica ni físicamente. Solo se invierte el objeto de su tendencia y, por lo tanto, podría llamarse homoerótico por inversión del objeto de amor o, más simplemente, homoerótico de objeto'. Según Ferenczi, el 'homoerotismo de objetos' sería una neurosis: más precisamente, una neurosis obsesiva. Al

\footnotetext{
39 SANDOR FERENCZI, Alcuni supplementi sul tema dell'omosessualità, en Fondamenti di psicoanalisi, Guaraldi, Rimini, 1974, vol. IV, pp. 134-40.

40 ID., L'homoérotisme: nosologie de l'homosexualité masculine, en OEuvres complètes, Payot, Paris 1970, vol. II, pp. 117-29.
} 
describir el 'homoerotismo de objeto' como un síndrome patológico, admite que se 'opone a Freud, quien, en su 'teoría de la sexualidad', define la homosexualidad como una perversión y la neurosis como un negativo de la perversión'.

Es evidente que, si la etiqueta de 'perversión' aplicada por Freud a la homosexualidad denuncia el trasfondo reaccionario de su posición hacia los homosexuales (aunque afirma 'lo inapropiado del uso moralista del nombre de perversión'), otros psicoanalistas, incluso muy cercanos a Freud -como Ferenczi-, pueden ser más abiertamente reaccionario definiendo la homosexualidad patológica en sí misma.

Por otro lado, en lo que respecta al homoerotismo, el pensamiento de Ferenczi resulta ser muy contradictorio: en algunos de sus escritos, en los que la cuestión homosexual se aborda de manera menos directa, es evidente que no puede evitar admitir, a continuación, la existencia de una homosexualidad congénita $\mathrm{y}$, por lo tanto, la presencia universal del deseo gay ${ }^{41}$. Pero entonces, si, como sugieren estos escritos, todos los seres humanos también deben ser considerados homosexuales, ¿todos estariamos sufriendo de neurosis obsesiva o de 'anomalía pura del desarrollo' debido a esto?

No: esto no podría ser porque, como se sabe, el doctor Ferenczi todavía distinguía entre 'neurótico' y 'sano'. Claramente, según su punto de vista, la homosexualidad se manifiesta como psiconeurosis o anomalia solo cuando se manifiesta precisamente al superar la resistencia y escapar de la represión.

Creo que interpreto la opinión de muchos homosexuales si digo que, por el contrario, creemos (y en esto nos acercamos al pensamiento de

41 En el escrito titulado Le rôle de l'homosexualité dans la pathogénie de la paranoïa Ferenczi, por ejemplo, afirma: 'El papel del alcohol [consiste] solo en la destrucción de la sublimación, lo que implica resaltar la verdadera estructura sexual psíquica del individuo, es decir, una elección de un objeto del mismo sexo' (cf. OEuvres complètes cit., vol. I, p. 176). La homosexualidad es, por lo tanto, no solo agradable, sino incluso 'la verdadera estructura sexual psíquica del individuo' ...

Se pueden citar otros escritos: Ferenczi está demostrando constantemente estar convencido de la presencia universal del deseo gay. Cf. por ejemplo: Symptômes transitoires au cours d'une psychanalyse en ibid., pp. 199-209; L'alcool et les névroses, en ibid., pp. 189-93; Un cas de paranoïa déclenchée par une excitation de la zone anale (donde se habla de 'sublimación social de la homosexualidad', en ibid., Págs. 146-49). 
Freud) que la neurosis general que afecta a todos depende en gran medida de la represión social del deseo gay y eso depende de su eliminación forzada y su conversión en síntomas patológicos.

Ferenczi no se aventura, plausiblemente, hasta esta 'conclusión'. Su condición privilegiada, de acuerdo con la Norma, de heterosexual masculino le impide descubrir el papel principal desempeñado por la represión de la homosexualidad en la etología de la neurosis que tortura a nuestra sociedad, la Kultur. Para descubrirlo, primero debe reconocer su propia 'neurosis obsesiva' y la anomalía de su desarrollo con respecto a una 'evolución' pansexual libre; en este punto, se daría cuenta de que no es posible estar realmente bien (volverse 'saludable') si no se libera su deseo erótico hacia personas del mismo sexo: la homosexualidad manifiesta no garantiza la felicidad por sí sola, pero no existe una auténtica liberación sin la liberación del deseo gay. Para sanar, debes elegir les fleurs du mal.

Notaremos que, en la mayoría de los estudios psiquiátricos sobre la homosexualidad, existe una tendencia a dividir la categoría de homosexuales 'masculinos' en compartimentos estancos (los 'homoeróticos de objeto' de Ferenczi) de lo 'femenino' (el 'homoerótico de sujeto'), según los modelos tradicionales opuestos de realización heterosexual, de la marcada diferenciación entre los sexos. Los psiquiatras y psicoanalistas que se dedican al estudio de la homosexualidad no pueden abstenerse de aplicarle categorias interpretativas puramente heterosexuales. ¿Y los antipsiquiatras? Ah, esos entienden a Lacan mejor de lo que entienden la homosexualidad ('En voulez-vous de Lacan? C'est meilleur que la banane...').

Así, filtrados por la interpretación psicoanalítica, los homosexuales parecemos completamente diferentes de lo que somos: mientras que, casi siempre, la opinión de los psicoanalistas se corresponde perfectamente con las ideas estereotipadas $y$ falaces que los heterosexuales ignorantes nos adjudican (y, en lo que concierne a la homosexualidad, todos los heterosexuales son, más o menos, ignorantes). Lejos de proceder desde la aparición de nuestra vida 'externa' de marginados, hasta el punto de comprender, a través del 
análisis crítico, la realidad de nuestra condición de homosexuales, el psicoanálisis, lleno de prejuicios, aplica categorias interpretativas preconcebidas a una visión heterosexual típica a la homosexualidad: en otras palabras, suma apariencia a la apariencia, fomentando la ilusión, obstaculizando las críticas, apoyando la ideología.

Posiciones sustancialmente equivalentes a las de Ferenczi se encuentran muy a menudo en la historia de la psiquiatría y el psicoanálisis. Muy frecuentemente, los médicos integran la gran mayoría o incluso la totalidad de los 'casos' de homosexualidad manifiestos en el marco de las neurosis, definiéndolos en términos psicopatológicos. Entonces, en su opinión, el homoerotismo sería una neurosis por 'fijación infantil de la libido y, sobre todo, fijación al estadio sádico-anal'; 'neurosis debido al no sepultamiento del complejo de Edipo, debido al narcisismo persistente'; 'neurosis por la eliminación de la heterosexualidad'; o 'por un desarrollo defectuoso de la primera infancia que consiste en haber recibido muy pronto una gran decepción del otro sexo' (Wilhelm Reich). Estos son los Leitmotives más comúnmente encontrados.

Luego están los que creen que la causa de la homosexualidad es el 'miedo pánico' del misterio de las mujeres (entre los hombres) y de los hombres (entre las mujeres): 'Consideramos la homosexualidad como una adaptación patológica, biológica y psicosexual, el resultado de los miedos en torno a la expresión de los impulsos heterosexuales' (Irving Bieber).

Tales hipótesis son inmediatamente acríticas e ilusorias tan pronto como nos damos cuenta de cómo parten del prejuicio de que la heterosexualidad, por el contrario, debe considerarse 'normal' en un sentido absoluto. Y, sin embargo, si seguimos las teorias psicoanaliticas inherentes a la 'patogénesis' de la homosexualidad, no podemos evitar considerar, por analogía, también la heterosexualidad como una neurosis, neurosis por la eliminación de la homosexualidad, por ejemplo, o neurosis debido al miedo pánico de relaciones sexuales con personas del mismo sexo. Parafraseando a Bieber, podríamos decir: 'Consideramos que la heterosexualidad es una adaptación patológica, 
biológica, psicosexual, el resultado de los temores que rodean los impulsos homosexuales'.

No es divertido jugar a las escondidas con psicoanalistas (o mejor, psico-nazis) o adaptarse a una comparación en el asqueroso terreno que ellos eligen. Los doctores nos inundan con estupideces dictadas a su (in)conciencia por el tabú anti-homosexual, y ciertamente no es interesante considerar lo que dicen. Sin embargo, muchas personas todavía piensan que tienen razón y encuentran que sus opiniones confirman fielmente las suyas, por lo que la comparación no se puede evadir por completo. Creo que debemos tener en cuenta lo que escribe Domenico Tallone sobre la ecuación psiquiátrica homosexualidad = enfermedad de la: 'Realmente no nos gustaría tener que volver al argumento sobre un tema que es al menos imbécil si no fuera porque, desafortunadamente, la imbecilidad se las arregla para tomar mayor control que el simple sentido común, cuando se demuestra que está respaldado por títulos académicos que son aún más temerosos ya que están vacíos en contenido'42.

Está claro que, si no se acatan servilmente los prejuicios actuales sobre los cuales la heterosexualidad debe ser considerada 'normal', 'natural' y la homosexualidad 'anormal', 'contra-natura', decir que la mayoría de 'los casos de homosexualidad manifiesta son psicopatológicos, decir que el homoerotismo es una neurosis, nos obliga a admitir que la heterosexualidad es en sí misma psicopatológica, que la heterosexualidad es una enfermedad. Y luego nos preguntamos al servicio de qué y, sobre todo, al servicio de quiénes está continuar diagnosticando la 'neurosis' de los homosexuales, y nos damos cuenta de lo absurdo que es pretender 'curar' la homosexualidad como una 'enfermedad' a partir de un punto presumiblemente saludable, aunque en realidad neurótico, que es la visión heterosexual de los psico-nazis.

Por otro lado, ¿por qué juzgar el homoerotismo 'anormal', 'contranatura'? Si consideramos que el ser animal es un aspecto esencial de la 'naturaleza' del hombre, veremos cómo la homosexualidad es común

42 DOMENICO TALLONE, Gli stregoni del capitale, en La politica del corpo cit., p. 66. 
entre los animales, en algunas especies incluso está más extendida que la heterosexualidad, y la homosexualidad femenina y la masculina ${ }^{43}$. La homosexualidad es muy común entre los monos; además, muchos mamíferos sub-primates también son homosexuales, como el león, el delfín, el perro (¿quién no ha visto a dos perros cogiendo? ¿O dos perras?), el gato, el caballo, la oveja, la vaca, el cerdo, el conejo, el chanchito de indias, la rata, etc. Luego están principalmente las aves homosexuales (el pato, por ejemplo, además de todos los que conocemos...).

Sin embargo, este listado y tipo de evidencia no ayuda a abrir los ojos del terco. Los heterosexuales con anteojeras usan el concepto de 'naturaleza', así como el de 'contra-natura', de acuerdo a su propia conveniencia. Leamos lo que Eunialo De Michelis escribe en su ensayo titulado La homosexualidad como lo ve un moralista: '¿Y qué importa el argumento irresistible de que incluso en el reino animal hay amores contra la naturaleza? Esto puede ser inocente en las bestias, pero no en el hombre tanto como vive en función de algo (o también en función de algo) que lo distingue de las bestias'44.

Por lo tanto, perdamos a los animales, dado que ellos también aman 'contra la naturaleza' y que el hombre vive en función de algo (De Michelis dixit). Sin embargo, por su parte, los antropólogos Clellan Ford y Franck Beach se han cerciorado de que, teniendo en cuenta 76 formas diferentes de sociedades humanas, solo el 27 (o el 36 por ciento) de la homosexualidad es desaprobada y más o menos reprimida. El tabú anti-homosexual que caracteriza a nuestra civilización occidental, por lo tanto, no es un dato estructural específico de la "naturaleza humana' y tiene un cierto origen histórico, aunque misterioso: Sodoma y Gomorra no fueron absolutamente destruidas ${ }^{45}$.

\footnotetext{
43 Cfr. CLELLAN FORD y FRANCK BEACH, Il sesso: nel comportamento degli uomini e degli animali, Schwarz, Firenze, 1961.

${ }^{44}$ EURIALO DE MICHELIS, L'omosessualità vista da un moralista, "Ulisse», fasc. XVIII, p. 733.

${ }^{45}$ Cfr. cap. II, par. 2.
} 
Finalmente, ya hemos visto cómo el psicoanálisis, por boca de Freud, declara la presencia universal del deseo homoerótico en los seres humanos. De todo esto deduciremos que la heterosexualidad, precisamente porque basa su presunta primacía en la afirmación completamente falsa de que la homosexualidad es 'contranatura', 'anormal' o 'patológica', demuestra ser patológica. Más precisamente: si el amor de un ser humano por otro sexo 'opuesto' no es en absolutamente patológico, la heterosexualidad tal como lo es hoy, como Norma, es patológica, ya que su primacía se mantiene despóticamente sobre la represión de otras tendencias del Eros. La tiranía heterosexual es uno de los factores que determinan la neurosis moderna y dialécticamente- también es uno de los síntomas más graves de esta neurosis.

En su delirio, varios psiquiatras y psicoanalistas, policias del poder capitalista heterosexual, distinguen, desde el punto de vista médicopsicológico, diferentes tipos de homosexualidad: según ellos, uno no debería hablar de homosexualidad, sino de la homosexualidad. Entonces, de la misma manera, podríamos hablar de la heterosexualidad en lugar de heterosexualidad.

Hay médicos que distinguen los diferentes tipos de homosexualidad según la edad del 'objeto' amoroso: pedofilia o pederastia, si es niño y adolescente, gerontofilia si es mayor. Pero, ¿`si el 'objeto' sexual no es ni viejo ni joven?

Y luego, al menos en lo que respecta a la pedofilia, la etimología griega no hace distinción de sexo: пaĩs, пaı́ós, significa niño y niña. Entonces ¿debemos distinguir la heterosexualidad pederastica de otras formas de heterosexualidad? En realidad, cuando, con repugnancia suprema, los llamados 'normales' se apoderan de la 'perversión' pederasta en las relaciones entre personas de diferentes sexos, ciertamente no hablan de heterosexualidad -ya que la heterosexualidad es para ellos sinónimo de 'normalidad'- ni de pederastia -ya que su ignorancia los lleva a considerar el término 'pederastia' como un sinónimo cercano de homosexualidad masculina-, pero hablan de 'perversión' tout court, o peor de 'crimen atroz': para el 'normal', el 
heterosexual que sale con un niño, no es un heterosexual, sino un monstruo. Pero Lolita vende mucho. Se encuentra en los estantes, en las fantasias y en los secretos de las mejores familias.

También hay médicos que se esmeran en distinguir la homosexualidad de acuerdo con las modalidades, por así decirlo, de 'técnica amatoria' (sodomía, vendaje, etc.). Pero, de nuevo, si diversos homosexuales pueden coexistir en un individuo ¿cuál es el punto de distinguir? Si se entrega al coito anal, felatio, besos, caricias, masturbación: de forma alternativa o simultánea (¡sexo!), ¿si es activo o pasivo alternadamente con la pareja o activo y pasivo con dos parejas? Y luego, desde el punto de vista de la 'técnica amatoria', en una sola persona puede coexistir una heterosexualidad diversa: la heterosexualidad sodomita, por ejemplo, por qué no, incluso si el Último tango fue condenado a muerte y la heterosexualidad genital frontal muy tradicional. Finalmente, ¿qué diría un doctor Azzeccagarbugli sobre aquellos que se entregan simultáneamente a diversos heterosexuales y diversos homosexuales? ¿De ese sujeto que, por ejemplo, mientras se hace penetrar el ano con el puño de su hermana, culea al amante macho de su hermana y mientras tanto masturba a la hermanita del amante de su hermana y le hace una mamada a su suegro? (¿suegro de quién?).

Con todas sus distinciones tan inútiles como grandilocuentes, nuestros médicos tienden a parecerse a la figura del tío (solo para quedarse en la familia) en la poesía de Catullo:

Sobre quién dice o hace cosas eróticas

El tío de Gellio exclamó y resonó.

Gellio escapó de toda censura:

Culeando a la esposa del tío

Hizo de él la estatua del silencio.

Si culeara también a su tío

El tío no hablaria ${ }^{46}$.

${ }^{46}$ CATULLO, Le poesie, Einaudi, Torino 1969, p. 238. 
Aún más ridícula es la distinción que hacen ciertos psico-nazis en relación con las características del vínculo homosexual: 'relación con un nivel sexual puramente instintivo o un amor erótico más complejo' (Tullio Bazzi). Y sin embargo, es precisamente este tipo de diferenciación lo que le permite a la Iglesia hoy juzgar más o menos pecaminosas las relaciones homosexuales, dependiendo de su carácter; más o menos pecaminosas, porque los pecados en cualquier caso son en función de la moral católica.

Finalmente, para tranquilizarse, los médicos suelen distinguir las formas de 'verdadera homosexualidad' de otras formas de 'homosexualidad espuria o pseudo-homosexualidad' (Bergler, Schneider, Servadio, por nombrar algunos 'buenos' campeones).

1) La 'homosexualidad real' ocurriría solo cuando 'un hombre con directrices femeninas recurra a un hombre con directrices masculinas y un cuerpo masculino'47. Solo en este caso, según los médicos, existe una 'inversión psicosexual del sujeto'.

2) En cambio, no se debe hablar de 'verdadera inversión sexual' cuando un hombre con 'directrices masculinas' se convierte en un hombre con un cuerpo de 'directrices masculinas y feminoides': en este caso no sería 'verdadera homosexualidad', en cuanto -según los médicos- el 'objeto' no podría amar al 'sujeto'. Pero, ¿por qué no debería poder amarlo? ¿Acaso no podría surgir en él, a pesar de las 'directrices masculinas' (que los médicos evidentemente combinan con el deseo heterosexual), el componente homosexual hasta ahora latente? Las maricas sabemos perfectamente que no hay heterosexuales inexpugnables: es suficiente saber cómo abordarlos en el momento adecuado (no cambia si tienen un cuerpo 'feminoide' o 'viril'). 'Un homosexual con algo de experiencia puede encontrar sin duda un mayor número de parejas entre los hombres que un hombre

47 TULLIO BAZZI, L'omosessualità e la psicoterapia, "Ulisse", fasc. XVIII, p. 648 ALFEED C. KINSEY, WARDELL B. POMEROY e CLYDE E. MARTIN, Homosexual Outlet, in The Homosexual Dialectic, Prentice-Hall (Inc.), Englewood Cliffs (N.J.), 1972, p. 15. Trad. it. in Il comportamento sessuale dell'uomo, Bompiani, Milano, 1950. 
heterosexual con algo de experiencia entre las mujeres' (Kinsey) ${ }^{48}$. Nada más alegre que coger con el chico que estaba convencido de que no sentía atracción sexual por los hombres y luego, gracias a tu habilidad artística para seducir, advierte que arde de deseo en tus brazos. La diferenciación médica entre 'verdadera homosexualidad' y 'pseudohomosexualidad' es exagerada: la homosexualidad siempre es cierta y existe incluso cuando no irrumpe; es decir, cuando yace latente.

Incluso con respecto al (cont)acto homosexual femenino o masculino, es correcto lo que dice Hegel: el acto 'es tal y tal, y su ser no es un simple símbolo, es el hecho mismo. Es esto, y el ser humano individual es lo que es el acto. Por el simple hecho de que el acto es, el individuo es para otros lo que realmente es, y con una cierta naturaleza general, y deja de ser simplemente algo que se 'entiende' o se 'presume' que es de cierta manera. [...]. Los actos por sí solos deben considerarse genuinos, no por su forma o modalidad [...]'.

3) Pero los médicos evidentemente no leyeron a Hegel, a pesar de que combaten para traficar su mala 'filosofia' como ciencia. De hecho, de acuerdo con algunos de ellos no se puede hablar de verdadera homosexualidad', incluso en el 'caso de un hombre con las directrices de sexo masculino dirigida hacia un hombre con un cuerpo feminoide y directrices femeninas'49, incluso en esta situación -admitamos: ¡tienen un buen corazón!- 'se puede formar un vínculo correspondido'. De hecho, según los psico-nazis, mientras las 'directrices del 'sujeto' permanezcan masculinas, no se puede hablar de una auténtica inversión psicosexual del 'sujeto' y, por lo tanto, de 'verdadera homosexualidad'. Aquí los médicos, vinculados como están a la noción de 'inversión psicosexual del sujeto' como una condición sine qua non de la 'verdadera homosexualidad' y a la dicotomía ilusoria del 'sujeto' y del 'objeto' (donde inmediatamente salta a la vista que, en cambio, en una relación, cada sujeto es también un objeto, así como cada objeto es

\footnotetext{
48 ALFEED C. KINSEY, WARDELL B. POMEROY y CLYDE E. MARTIN, Homosexual Outlet, en The Homosexual Dialectic, Prentice-Hall (Inc.), Englewood Cliffs (N.J.), 1972, p. 15. Trad. it. en Il comportamento sessuale dell'uomo, Bompiani, Milano, 1950.

49 BAZZI, L’omosessualità, cit., p. 649.
} 
también un sujeto), no advierten que este tercer 'caso', considerado por ellos como una manifestación de 'homosexualidad espuria', es realmente simétrico, en cuanto a las 'directrices', el primer 'caso', la única forma -en su opinión- de 'verdadera homosexualidad'. De esta manera, al negar el atributo de reciprocidad al concepto de 'verdadera homosexualidad', niegan la posibilidad de una relación genuinamente homosexual, y reducen la 'verdadera homosexualidad' a una mera calificación de cierto tipo de 'sujeto'.

En resumen: para muchos psico-nazis, la homosexualidad es verdadera solo cuando va acompañada de lo que llaman inversión psicosexual del sujeto', ya que en este caso 'el sujeto tiene una psicosexualidad femenina y es comprensible que sienta atracción por el hombre ${ }^{50}$. Solo el uranista perfecto, por lo tanto, 'anima muliebris in corpore virili inclusa' (Ulrichs), seria verdaderamente una marica. Todas las demás pseudomaricas. Quién sabe por qué, en cambio, las personas generalmente le dicen marica a cualquier hombre que, de una forma $u$ otra, desee hacer el amor con otro hombre. ¿Ese sentido común popular sabe más que los médicos?

En realidad, no lleva mucho tiempo comprender que los médicos, a pesar de todos sus sofismas y definiciones distintas, siguen fomentando los clichés vulgares que se adhieren a las etiquetas heterosexuales 'interpretativas' de la homosexualidad: según ellos, debemos poseer 'directrices' psicosexuales femeninas para poder desear a un hombre. De lo contrario, la homosexualidad es 'pseudo-homosexualidad'. Por el contrario, es evidente que el tipo de situación homosexual definida por ellos como 'verdadera homosexualidad' es la que más recuerda a la heterosexualidad. No son capaces de concebir la verdadera homosexualidad como una relación entre hombres y la reducen a un atributo esencial de cierto tipo de 'inversión' con deseos 'femeninos' dirigidos al hombre: el tabú antigay les impide comprender que el homoerotismo no es imitación de la heterosexualidad, pero sí les permite otra cosa, hace que vomiten ríos de mierda. 
En cambio (incluso sin haber leido a Hegel) consideramos verdaderamente homosexuales a todo tipo de deseos, actos y relaciones sexuales entre personas del mismo sexo: ¿obvio? Por supuesto, pero bien podemos decir que, de la homosexualidad, los heterosexuales ignorantes saben considerablemente menos que La Palice.

La relación erótica ocasional de una mujer con una mujer que generalmente solo tiene relaciones con hombres (no cambia si es consciente de ello o no) también es verdaderamente homosexual; la relación casual de un hombre con un hombre que generalmente tiene relaciones con mujeres (lo admita o no) también es verdaderamente homosexual.

Según Kinsey, Pomeroy y Martin, en lugar de usar los términos 'heterosexual' y 'homosexual' como 'sustantivos que definen a las personas, o como adjetivos para describir a las personas, uno podría usarlos más adecuadamente para describir la naturaleza de las relaciones sexuales manifiestas o el estímulo a lo que un individuo eróticamente responde'. Después de todo, no están equivocados, a pesar de que su propuesta resulta ser, de hecho, abstracta o, en cualquier caso, abstraida de los hechos: porque, dado el contraste histórico concreto entre individuos que reconocen sus propios deseos homoeróticos y otros que los niegan, hoy no podemos evitar distinguir a los homosexuales manifiestos de los heterosexuales (es decir, de las maricas decididamente réfoulées). De lo contrario, se produciría un aplastamiento terminológico peligroso e ilusorio de la contradicción real existente entre la heterosexualidad y la homosexualidad: en esta noche, no todas las vacas son gay.

Pero volvamos a las opiniones de los hetero. Muchas personas piensan que, a veces, debido a ciertos factores ambientales externos, el comportamiento homosexual asume el significado de una satisfacción puramente instintiva y paliativa: sería una especie de homosexualidad sustitutiva', destinado a desaparecer con la situación cambiante del ambiente. Esto ocurriría especialmente entre miembros de 'comunidades' masculinas que no pueden tener relaciones con mujeres y mujeres forzadas a vivir en 'comunidades' femeninas donde las 
reuniones con hombres están prohibidas (prisiones, campos de concentración, universidades, conventos, barcos, cuarteles, etc.). En realidad, incluso en estos casos es ilusorio hablar de 'pseudohomosexualidad' o 'homosexualidad sustitutiva': debe haber expresiones manifiestas reconocidas de deseo homoerótico que, si estaban latente antes, ahora emergen, dadas las condiciones ambientales particulares, más o menos enajenados (y alienados, sí, debido a condiciones ambientales restrictivas e inhumanas).

También hay médicos que no consideran que los homosexuales varones' sean prostitutas: los clasifican como 'psicópatas amorales' (Tullio Bazzi). Pero entonces, ¿los hombres que se prostituyen como mujeres no serian verdaderos heterosexuales? ¿O los hombres que se prostituyen con mujeres no están, según los médicos, en la categoría de 'psicópatas amorales'?

En cualquier caso, en el 'trabajador sexual' reconocemos a los homosexuales que, debido a la represión del homoerotismo y la pobreza en la que se ven obligados a vivir, pueden dar lugar a sus impulsos homoeróticos solo citando en sus propios ojos y en los de los demás la necesidad (por muy engañosa que sea de la homosexualidad) de ganar dinero ${ }^{51}$. Incluso en el caso de la prostituta que va con hombres, lo que dice Hegel es válido: '...cuando su actividad se opone a sus posibilidades, capacidades o intenciones internas, solo la primera debe considerarse como su verdadera realidad, incluso en el caso de que se engañe a sí mismo al respecto $y$, tras pasar de la acción a sí mismo, tiene la intención de ser, en su 'mundo interior', algo diferente de lo que fue en el acto'.

Para concluir, me referiré a la opinión de quienes consideran 'psiconeurótica' solo la homosexualidad de quienes, lejos de estar orgullosos de ella, se avergüenzan, temen, se preocupan por ella y tratan de deshacerse de ella. Pero entonces, de la misma manera, podemos definir a todos los heterosexuales como psiconeuroticos que niegan absolutamente la presencia de impulsos homosexuales en sí

${ }^{51}$ Cfr. cap. IV, par. 3. 
mismos, porque esta negación absoluta revela su miedo a reconocer su propia homosexualidad, que no aceptan: en una palabra, su naturaleza como criptomaricas. Los homosexuales que se avergüenzan de serlo son tan neuróticos como la sociedad heterosexual que rechaza el homoerotismo, juzgándolo vergonzoso y abyecto, y condenándolo a latencia o marginación. Los homosexuales que preferirian ser heterosexuales son la imagen especular de una sociedad que reprime el homoerotismo.

Cuando, en cambio, una persona gay 'se acepta', en el campo psicoterapéutico muchos reconocen que los resultados son escasos o nulos en los raros sujetos que se han prestado a esta cura'52. Pero -se objetará- ¿cómo puede un homosexual aceptarse a sí mismo y al mismo tiempo someterse a una terapia como homosexual? Evidentemente, es suficiente para los médicos que una persona gay no cambie de día y de noche debido a su homosexualidad para definirlo como 'homosexual que se acepta' y, en cualquier caso, trata de 'curarlo': pero un hombre gay que realmente se acepta, se ama por lo que es y por las acciones que realiza, que ama a otros gays, nunca consentiría prestarse a ningún tipo de 'cura' que intente convertirlo en heterosexual (incluso si la enfermera fuera Delphine Seyrig).

En cualquier caso, incluso los psicoanalistas ortodoxos, generalmente tan optimistas en cuanto a las posibilidades de su método, son muy escépticos al respecto: Steckel afirma que 'nunca vio a un homosexual curado por el psicoanálisis', y Nacht (1950) cree que la forma 'es inaccesible para cualquier tipo de psicoterapia'53. Claramente, no se puede curar a alguien de una enfermedad que no tiene.

\section{Los llamados 'terapeutas'}

Queda por referirse a la opinión de quienes se aventuran a una cierta correlación entre el comportamiento homosexual y el equilibrio

\footnotetext{
52 BAZZI, L'omosessualità, cit., p. 654.

53 BAZZI, L'omosessualità, cit., p. 654.
} 
hormonal químico ('donde al menos está claro' -observa Aitmann de inmediato- 'que una correlación no puede convertirse fácilmente en una causa') ${ }^{54}$. Ya he dicho que los llamados 'desequilibrios' hormonales pueden ocurrirle indiferentemente tanto a los heterosexuales como a los homosexuales. 'Después de todo -el doctor Dreyfus nota de mala gana-, las dosis hormonales inyectadas de forma sistemática y en serie nunca han permitido establecer una fórmula hormonal propia de la homosexualidad'55.

Esto no impide que los médicos, como nazis perfectos, se deleiten en experimentos de 'terapia' hormonal de la homosexualidad: el 'invertido' puede ser un conejillo de indias. Sin embargo, el propio Dreyfus se ve obligado a admitir: 'Desafortunadamente, nunca he visto una homosexualidad masculina, cualquiera que sea el sustrato biológico, sanar bajo la sola influencia de una cura hormonal, incluso si se lleva a cabo enérgicamente'56.

Muchos médicos, así como criminales, también son imbéciles: muy a menudo tienden a confundir la homosexualidad con la 'masculinidad' en las mujeres o el 'afeminamiento' en los hombres. Esto sucedió a pesar del psicoanálisis -como hemos visto- desde la época en que Freud llegó a la conclusión de que 'la medida del hermafroditismo físico es en alto grado independiente de la del psíquico'57. Por lo tanto, independientemente de esta consideración y sus corolarios, llegamos a confesiones como la de Robert Stoller, un psiquiatra de Los Ángeles, que escribe: 'Los homosexuales masculinos son una excepción a la que no puedo referirme, porque todavía no los he entendido’. ¡Pero qué excepción ni excepción! Los homosexuales 'masculinos', especialmente en los Estados Unidos, son mucho más numerosos que los

54 DENNIS ALTMANN, Omosessuale: oppressione e liberazione, Arcana, Roma, 1974, p. 5 .

${ }^{55}$ DREYFUS, L'omosessualità, cit., p. 644.

56 Ibid.

57 FREUD, The psychogenesis, cit., p. 132. 
'afeminados', que, sin embargo, obviamente pasan menos desapercibidos.

Está claro que si un psicoanalista, a diferencia de Freud, considera que la homosexualidad en sí misma es patológica, se considerará inclinado a evaluar la posible y aconsejable 'terapia'. Hay quienes consideran que 'el pesimismo generalizado sobre los resultados de una intervención terapéutica de la homosexualidad es incorrecto' (Gian Franco Tedeschi).

Freud, por otro lado, al no identificar la homosexualidad con un síndrome patológico, enfatizó cómo, en psicoterapia, llevar la 'eliminar la inversión genital u homosexualidad, nunca resulta fácil'. 'He hallado, más bien, -escribió- que sólo se lo consigue bajo circunstancias particularmente favorables, y aun en esos casos el éxito consiste, en lo esencial, en que pudo abrírsele a la persona restringida a lo homosexual el camino hacia el otro sexo, que hasta entonces tenia bloqueado; vale decir, en que se le restableció su plena función bisexual. Depende después de su albedrío que quiera desertar de ese otro camino proscrito por la sociedad, y en casos singulares es lo que en efecto ha sucedido. Es preciso confesar que también la sexualidad normal descansa en una restricción de la elección de objeto, y en general la empresa de mudar a un homosexual declarado en un heterosexual no es mucho más promisoria que la inversa, sólo que a esta última jamás se la intenta, por buenas razones prácticas'58. 'Como regla, -concluye- el homosexual no puede resignar su objeto de placer; no se logra convencerlo de que, con la trasmudación, reencontraría en el otro objeto el placer a que renuncia. Si es que se somete a tratamiento, las más de las veces será porque motivos exteriores lo esforzaron a ello: las desventajas sociales y los peligros de su elección de objeto; y estos componentes de la pulsión de autoconservación demuestran ser demasiado débiles en la lucha contra las aspiraciones sexuales'. En otro lugar, escribiendo a la madre de uno de sus pacientes estadounidenses, Freud declara: 'En cierto número de casos hemos logrado despertar los gérmenes frustrados de

58 FREUD, The psychogenesis, cit., p. 129. 
las tendencias heterosexuales, que están presentes en todo homosexual, pero en la mayoría de los casos esto no es posible [...]. Lo que el psicoanálisis podria hacer por su hijo es algo muy diferente. Si se siente infeliz, neurótico, desgarrado por los conflictos, inhibido en su vida social... el análisis puede traerle armonía, paz mental, plena eficiencia'59.

Quizás esta carta contiene la posición, gradualmente, menos reaccionaria de Freud hacia la homosexualidad. Sin embargo, a pesar de su posición tolerante, que lo distancia de los psico-nazis como Ferenczi, Ernest Jones, GB Hadden, Irving Bieber, Erminio Gius, etc., Freud, perezoso, stands in the middle of the road $\mathrm{y}$ ante cualquier pregunta se lava las manos maravillosamente.

En unos pocos años, Wilhelm Reich habría revocado la concepción freudiana, afirmando que 'con un tratamiento psicológico particular cada homosexual puede dejar de serlo, mientras que nunca sucede que un individuo que se ha desarrollado normalmente se vuelva homosexual después de dicho tratamiento'. En general, Angelo Pezzana tiene razón cuando argumenta que 'lo que Reich escribió sobre la homosexualidad podria atraer al más ardiente de nuestros contemporáneos fascistas del sexo'60.

Sin embargo, los reichianos, deseosos o a regañadientes, llegan a la otra orilla, ya que el movimiento feminista y el movimiento gay han desarrollado un número creciente de niñas y niños, hasta ayer exclusivamente heterosexuales: en otras palabras, cada vez más personas dejan de eliminar sus deseos homosexuales. Las 'buenas razones prácticas' por las cuales Freud no consideró conveniente inducir en la homosexualidad, a través del análisis, un colapso heterosexual. El homoerotismo corroe los márgenes de censura y se extiende: gracias a la lucha de los gays, el mundo se vuelve más gay. Muchos jóvenes heterosexuales se dan cuenta de que, al dejarse 'contagiar' por homosexuales, descubren la terapia más favorable para

59 ID., Lettera a una madre americana, "American Journal of Psychiatry", n. 108, 1951, p. 252.

60 ANGELO PEZZANA, Contro Reich, en La politica del corpo cit., p. 75. 
la solución de muchos de sus problemas. 'Gay is healthy', sonó un eslogan articulado durante las primeras manifestaciones del Gay Liberation Front americano.

Pero los verdugos no se rinden. Muchos psiquiatras modernos perseveran en dedicarse al 'cuidado' de las personas 'afectadas' por la homosexualidad recurriendo no sólo al tratamiento hormonal, sino también a la psicofarmacéutica y la psicoterapia, la terapia de electrochoque y, ¿por qué no?, la terapia de aversión ${ }^{61}$. Los crímenes de

61 Cfr. DON JACKSON, Dachau for queers, en The Gay Liberation Book, Ramparts Press, San Francisco, 1973, pp. 42-49, donde se habla de las increíbles torturas a las que son sometidos los homosexuales en ciertas clínicas estadounidenses. La terapia de aversión (¿recuerda la película La naranja mecánica?) consiste en mostrar al 'paciente' imágenes pornográficas de tipo homosexual, sometiéndolo a un electrochoque -a través de un mecanismo ligado al pene- cada vez que alcanza una erección. Las consecuencias nocivas son imaginables (o casi). Con mucho gusto colgaría con mis propias manos a los médicos que practican la terapia de aversión.

En la Unión Soviética -donde, como en los Estados Unidos, está permitido el uso del electrochoque en la 'terapia' de la homosexualidad, el tratamiento más popular se basa en la apomorfina. ¿De qué se trata? Cito de "L'Espresso", n. 22, XXII, 30 de mayo de 1976, el artículo titulado Rapporto sui comportamenti sessuali in Urss: deviazionista! que contiene amplios extractos del libro Sessuopatologia femminile de A. M. Svjadosc, director del laboratorio de sexopatología de Leningrado: 'Tomamos una solución, recién preparada, de clorhidrato de apomorfina al uno por ciento. Cinco minutos después de la inyección, la apomorfina causa náuseas, acompañada de latidos cardíacos y una leve falta de aliento y vómitos. El paciente no está informado sobre los efectos de la apomorfina: cree que le dan un medicamento contra las tendencias homosexuales. Todas las ideas e imágenes ligadas al objeto homosexual y los actos homosexuales se volverán repulsivas y desagradables. Al comienzo del tratamiento, se inyectan una o dos décimas de miligramo de apomorfina en una solución del uno por ciento. Tres a cuatro minutos después de la inyección, se inculca al paciente indiferencia hacia la pareja y los actos homosexuales. Luego se le pidió que mire la fotografia de su pareja o que imaginara las relaciones homosexuales que tenía con él. La sensación de náuseas y vómitos, causada por la apomorfina, se relaciona con la relación homosexual que adquiere un significado negativo. Si la dosis inicial de apomorfina no ha causado náuseas o vómitos, la dosis debe aumentarse. La terapia con apomorfina se realiza antes del almuerzo o dos horas después de comer. Después de doce o quince inyecciones, la apomorfina puede reemplazarse con una solución fisiológica. Es aconsejable acompañar la terapia de apomorfina con sugerencias y consejos: al principio convencerá al paciente de que es indiferente, luego siente disgusto por la pareja y por los actos homosexuales. Este método se ha utilizado con éxito para eliminar la homosexualidad en sujetos masculinos activos'.

Como se puede ver, los psico-nazis soviéticos usan despreocupadamente la palabra 'enfermo' para definir al homosexual; y los editores de "L'Espresso" se comportan, como es costumbre, de una manera reaccionaria, limitándose a informar -sin desperdiciar comentarios críticos- extractos del texto soviético, traducidos con el descuido habitual. Evidentemente, el italiano 'progresista' anti-homosexual disfrutará 
los que están manchados son muy graves y el capital de hoy les permite actuar con impunidad tal como el capital de ayer favoreció los monstruosos experimentos médicos de las SS.

Mientras tanto, lo que se etiqueta como 'perverso' sigue siendo, a los ojos de la gran mayoría, absolutamente y vergonzosamente aberrante y, como tal, susceptible a la condena (in)moral e (in)civil. La opinión pública, esclava de la ideología de la época, no tiene en cuenta el valor históricamente relativo de las definiciones de 'perversión'. También en este caso, 'la normatividad natural de la sociedad es la ideología, ya que se hipostatizan como un dato natural e inmutable' (Adorno).

Quienes piden hoy sanciones penales severas contra la homosexualidad ciertamente no tienen en cuenta el hecho de que, hasta no hace muchas décadas, la legislación de varios estados industriales condenó algunos actos sexuales, como la masturbación, la fellatio y el cunnilingus, actualmente considerados mayormente 'normales'62. Aquellos que desprecian a los homosexuales, los 'invertidos', ciertamente no tienen escrúpulos sobre el supuesto valor absoluto de su (pre)juicio. De hecho, la gran masa piensa eso y la opinión de la mayoría de los 'niños-hombres' y de los 'filósofos-niños' (Hermann Hesse) se hace pasar por un juicio verdadero y, por lo tanto, absoluto. La ideología capitalista es decididamente antihomosexual: la ciencia psiquiátrica y el psicoanálisis, que en la cultura burguesa se afirman y desarrollan, casi siempre resaltan los lugares comunes. La naturalidad del statu quo social y sexual, respaldada por la ideología dominante, no es realmente cuestionada por la investigación científica. Es cierto que ahora existe una antipsiquiatría y un antipsicoanálisis:

de tal lectura con placer: jen Rusia al menos, a los maricones los tratan adecuadamente!

Por lo tanto, incluso a los médicos soviéticos (y a los editores de 'L 'Espresso') con gusto los colgaría con mis propias manos. Pero no tengo suficientes manos: de hecho, los maoístas de nuestros propios países serian todos hechos pedazos, si consideramos que en China los homosexuales son fusilados si son atrapados en 'flagrante' después de un período de varios años de 'reeducación forzada (y este tratamiento estaba reservado para ellos incluso cuando vivía el santo Mao Tse-tung).

62 Cfr., por ejemplo, NELL KIMBALL, Memorie di una maîtresse americana, Adelphi, Milano, 1975, p. 3. 
pero ellos mismos caen esencialmente en esa naturaleza unidimensional del pensamiento científico contemporáneo, que el movimiento de liberación homosexual contribuye a criticar. Caen dentro de la dimensión camaleónica del dominio real del capital.

\section{El dogma de la procreación}

En los Tres ensayos de una teoría sexual (1905), Freud llega a la conclusión de 'que el material presentado hasta aquí no nos habilita para esclarecer satisfactoriamente la génesis de la inversión'63: me parece al menos contradictorio investigar la génesis de la homosexualidad cuando se ha descubierto que la homosexualidad es congénita. Sin embargo, en un trabajo posterior, Freud diria: 'No es misión del psicoanálisis solucionar el problema de la homosexualidad'64.

Por otro lado, es indudablemente cierto que los homosexuales no sufrimos por la 'inversión', sino por la persecución socialmente perpetrada contra nosotros: ‘ $\mathrm{E}$ l homosexual sufre represión y no su homosexualidad!' (Domenico Tallone). Por lo tanto, es evidente que, mucho más que el 'origen' de nuestra homosexualidad, estamos interesados en identificar y centrarnos en los motivos de su persecución, a fin de hacer que la batalla contra la que luchamos sea más clara y efectiva. Si se intenta esbozar una etiología del comportamiento homosexual, ¿por qué no investigar simultáneamente las razones para la fijación del deseo, por parte de la mayoría, en los 'objetos' de sexo 'opuesto'. Las dos preguntas son complementarias, ni una puede arrojar luz sobre la otra sin cuestionarla. Ciertamente, una investigación etiológica completa, que también toma en cuenta la segunda pregunta, y no evita enfrentarla con el pretexto de que se trata de la disposición erótica y el comportamiento definido como 'normal', podría contribuir válidamente al descubrimiento de las motivaciones

63 FREUD, Tre saggi cit., p. 45.

${ }^{64}$ ID., The psychogenesis cit., p. 148. 
que determinan la persecución de la homosexualidad. Como dice René Schérer, no deberíamos preguntarnos por qué los seres humanos 'pueden volverse homosexuales, sino por qué la educación los ha llevado a establecer una diferencia entre los sexos capaz de darles placer hasta el punto de desarrollar, comenzando por la ambivalencia absoluto de la infancia, una heterosexualidad exclusiva'65.

Comúnmente, la heterosexualidad 'normal' se considera en virtud de la ecuación amor $=$ procreación. Nada podría ser más falaz: el deseo erótico y la reproducción de la especie no coinciden. Considerar la sexualidad como dirigida a la reproducción significa aplicar una categoría interpretativa teleológica-heterosexual $y$, por lo tanto, reductiva, al complejo múltiple de funciones libidinales existentes. Como escribe Georg Groddeck, 'el intento de derivar el fenómeno del Eros a partir del instinto de reproducción es una de las idioteces más colosales de nuestro siglo: cada manzano en flor, cada brote, cada trabajo del hombre simplemente refutan esta interpretación limitada de los propósitos de la naturaleza divina. De los veinte mil óvulos destinados a ser fertilizados, de los cuales la niña está dotada al nacer, en el momento de la pubertad solo quedan unos cientos, y de estos, en el mejor de los casos, solo una docena se fertiliza realmente; de los muchos millones de espermatozoides con los que está dotado el hombre, innumerables huéspedes mueren sin siquiera llegar al útero femenino. La gente dice una montaña de tonterias'66.

La procreación procede de un acto sexual que está lejos de agotar en sí mismo todo el vasto alcance del deseo, toda la amplia gama de sus matices. Gide señala cómo, "lejos de ser lo único 'natural', el acto procreativo, en la naturaleza, entre las profusiones más desconcertantes, es a menudo un evento fortuito. - $Y$ agrega:- la voluptuosidad que trae consigo el acto de la fertilización, en un sexo y en el otro, no está necesariamente [...] y exclusivamente vinculada a este acto". 'No es la fertilización lo que busca el animal, es simplemente

65 RENÉ SCHÉRER, Emilio pervertito, Emme Edizioni, Milano, 1976, p. 74.

66 GRODDECK, Il libro dell’Es, cit., p. 131. 
voluptuosidad. Busque la voluptuosidad y encuentre la fertilización por casualidad'67.

En cuanto a los animales, también en lo que respecta a la especie humana, considerar necesariamente la procreación como el propósito del sexo significa mistificar el sexo heterosexual dándole una finalidad metafísica'; significa desconocer el placer en primer lugar como un fin en sí mismo, o más bien como un fin para satisfacer la pulsión sexual; significa ser hipócritas.

En la naturaleza, el sexo no se usa exclusivamente para la reproducción; al contrario, porque entre tantas especies animales las hembras entrarian en celo durante períodos cortos del año (estaciones de inspiración), mientras que los machos pueden decir que no conocen pausas. Y luego, justo cuando están en celo, las féminas frecuentemente se entregan a la homosexualidad. La cerda 'actúa como un jabalî', la yegua 'actúa como un semental', la vaca 'actúa como un toro' 'monta' a otras hembras y, a menudo, a los mismos machos ${ }^{68}$.

Muchas personas perciben un fin en la sexualidad (procreación), pero olvidan que la teleología es una forma de su propio juicio: y así, al olvidarlo, tiende a absolutizarlo, superponiendo en la experiencia de la naturaleza una particularidad históricamente determinada del pensamiento humano, una forma particular de juicio, justo en el momento en que, por el contrario, es necesaria una suspensión de juicio para comprender qué es realmente el Eros más allá de todos los prejuicios y, finalmente, vivirlo y disfrutarlo en libertad.

La persecución de la homosexualidad encaja plenamente en el marco más amplio de la represión sexual general. El dogma de la procreación como el único fin verdadero de la sexualidad ha surgido históricamente como una corona ideológica para la reducción efectiva del Eros a la heterosexualidad monógama $\mathrm{y}$, al mismo tiempo, como una justificación para la condena emitida por las sociedades contra todas las demás tendencias libidinales, de modo que fueron sublimados en la esfera 67 ANDRÉ GIDE, Corydon, Dall'Oglio, Milano, 1952, p. 83.

68 Cfr. ENRICO FULCHIGNONI, L'omosessualità nelle donne, "Ulisse», fasc. XVIII, p. 709. 
económica. Era necesario implicar que la sexualidad tenía como objetivo la reproducción, para ocultar el auténtico propósito de la represión sexual: la explotación de mujeres y hombres en la producción. Volveré más adelante sobre este argumento fundamental 69.

En cualquier caso, podemos observar de ahora en adelante lo absurdo que es continuar rechazando la homosexualidad porque sea extraña a la procreación, cuando el planeta sufre, entre otras cosas, debido a superpoblación. Sobre todo, la sobrepoblación está determinada por la persistencia represiva de los tabúes antigay.

Por otro lado, el dogma de la procreación como el único fin auténtico de la sexualidad es parte de la religión y cultura patriarcales. Es, por lo tanto, una expresión de sociedades masculinas, en las que la mujer, que es el verdadero sujeto de la reproducción (el hombre no genera, coge), está represivamente vinculada a un papel subordinado.

Ahora -señala Adriana Guardigli-, está claro que solo las mujeres pueden descubrir y saber en qué consiste realmente la procreación y con qué tienen que ver la reproducción y la sexualidad. Por otro lado, al reprimir a las mujeres y la sexualidad, la sociedad reprime el instinto de procreación que es parte del Eros y especialmente del Eros femenino. Puede ser que las relaciones actuales de ambivalencia entre padres e hijos (odio y amor) también estén vinculadas a la represión de este instinto.

El dogma de la procreación, por lo tanto, no solo expresa en general la represión de la sexualidad, sino también -en particular- la alienación del instinto de procreación, que en realidad fue eliminado de la especie y que emerge sólo en forma de extraordinarias 'reminiscencias' en las experiencias de la maternidad.

\section{Edipo u otro}

El trabajo en este campo es un trabajo pionero. A menudo me equivoqué y muchas veces tuve que cambiar de opinión. Pero lo sé y, por lo tanto, me he adaptado a esta regla: como el día solo puede nacer de la noche, incluso la verdad nace del error.

${ }^{69}$ Cfr. cap. VI, par. 4. 
En última instancia, todavía no es posible explicar por qué algunas personas devienen gay y otras hetero.

No es dificil entender por qué la mayoría de las personas son heterosexuales y pocos homosexuales: esto -ya lo he dicho-depende de la represión social, que tiende a reducir la riqueza polimorfa original del Eros (transexualidad) a la heterosexualidad rígida. Por qué, sin embargo, algunos, a pesar de la dura condena de las tendencias homosexuales, se vuelven homosexuales, es lo que por el momento no se puede explicar. Cómo, si bien resumimos todas las diferentes hipótesis formuladas hasta ahora en torno a las causas de la afirmación histórica del tabú anti-homosexual, todavía no llegamos a una explicación exhaustiva y segura, por lo que es muy dificil establecer qué nos indujo a los gays a no identificarnos con la Norma y reconocer nuestro deseo en la homosexualidad.

La homosexualidad es tan antigua como la especie e incluso más antigua y siempre se renueva, sin embargo, en este campo, los primeros pasos de aclaración se están dando hoy. Y como la voz de los homosexuales suele estar limitada por la represión del silencio, se sabe muy poco. Podriamos, si quisiéramos, revisar las diferentes opiniones de los psicoanalistas psico-nazis sobre las razones que determinan la afirmación predominante del deseo homosexual. Pero esto ya lo han hecho otros ${ }^{71}$, a decir verdad con malos resultados. En general, entonces, volvemos al psicoanálisis en un intento de 'cimentar científicamente', de una forma u otra, nuestro propio juicio más o menos contrario a la homosexualidad. Yo, por otro lado, quiero arrojar luz sobre el tema en la perspectiva práctica de la liberación: por lo

70 CARL G. JUNG, Psicologia dell'inconscio, Boringhieri, Torino, 1973, p. 182.

${ }^{71}$ Cfr., por ejemplo, ERMINIO GIUS, Una messa a punto dell'omosessualità, Marietti, Torino, 1972. Este es uno de los trabajos más reaccionarios sobre el homoerotismo publicado en Italia en los últimos años. El autor es sacerdote (o cuasi-sacerdote), profesor, por desgracia, en la Facultad de Psicología de la Universidad de Padua. Llega a citar, por ejemplo, entre las diversas opiniones 'científicas' recopiladas, el punto de vista de Gino Olivari, por ejemplo, un canalla que durante años se ha dedicado impunemente a los experimentos más absurdos de 'terapia' de la homosexualidad. 
tanto, solo consideraré dos o tres teorías, inherentes a la relación entre la homosexualidad y el complejo de Edipo; teorias que, en un sentido u otro, despiertan cierto interés en mí.

Hay quienes consideran que la heterosexualidad es una solución 'normal' del complejo de Edipo, y la homosexualidad una solución 'invertida'. Pero no me parece suficiente atribuir a la exasperación particular, a la amargura profunda, a sentirse irremediablemente traicionado, el distanciamiento drástico del 'objeto' femenino por parte de aquellos que se convertirán en homosexuales, quienes, una vez que han comprobado que la madre que aman pertenece exclusivamente al rival odiado, el padre, renunciarian a ella como a cualquier otra mujer, volviendo su deseo al 'objeto' masculino. Una interpretación similar, mutatis mutandis, nos ofrece Freud en un 'caso' de homosexualidad femenina ${ }^{72}$.

Pero, ¿qué factores específicos determinan la eliminación del sexo del progenitor amado en lugar de la concentración del deseo en él? En otras palabras, desde el punto de vista de Edipo, ¿qué diferencia ab origine al hetero de los gays? Dado que, basándose en la concepción clásica del complejo de Edipo en su forma 'normal' o 'positiva', incluso aquellos que se vuelven heterosexuales se exasperan, se sienten traicionados $\mathrm{y}$ amargados ante la evidencia de la superioridad y exclusividad de la relación parental que impide la realización de la relación amorosa deseada de la hija con el padre, del hijo con la madre. Y, sin embargo, si son hombres, no renuncian al sexo femenino como han tenido que renunciar a su madre: por el contrario, fijan el 'objeto' de su propio poder sexual; mientras que las mujeres sí, centran su deseo en el sexo masculino, en lugar de alejarse de él. Freud sospecha la existencia 'de algún factor especial que ha favorecido definitivamente una parte en lugar de la otra [heterosexualidad u homosexualidad, y que tal vez solo esperó el momento apropiado para inclinar la elección del objeto en su dirección'73. Pero no agrega nada más.

${ }^{72}$ Cfr FREUD, The psychogenesis, cit., p. 135.

73 Ibid. 
Según muchos psicoanalistas, al ingresar a la fase edipica, las características del complejo y su declive están determinadas por la forma en que se han cruzado las fases oral y anal. La escuela inglesa de psicoanálisis insiste en la importancia de la agresión oral infantil, de sus 'proyecciones' y de su función en la afirmación de la homosexualidad. En el ensayo Un recuerdo infantil de Leonardo da Vinci (1910), Freud considera la 'fijación' oral al pene como un desplazamiento directo del afecto primario hacia el pecho. La homosexualidad deriva de la 'fijación de la necesidad de amar a la madre'74.

En 1921, Freud llega a esta conclusión: 'La génesis de la homosexualidad masculina es, en una gran serie de casos, la siguiente: el joven ha estado fijado a su madre, en el sentido del complejo de Edipo, durante un tiempo y con una intensidad inusualmente grandes. Por fin, al completarse el proceso de la pubertad, llega el momento de permutar a la madre por otro objeto sexual. Sobreviene entonces una

${ }^{74}$ FREUD, Un ricordo d'infanzia di Leonardo da Vinci, en Saggi sull'arte, la letteratura e il linguaggio, Boringhieri, Torino, 1969, vol. I, p. 155. En Nel Caso clinico del piccolo Hans (1908), Freud plantea la siguiente hipótesis: 'En quienes después serán homosexuales -que según mi predicción, confirmada por las observaciones de Sadgerhallamos la misma preponderancia infantil de la zona genital, en especial del pene. Más aún: esta elevada estimación por el miembro masculino se convierte en destino para ellos. Escogen a la mujer como objeto sexual en su infancia mientras presuponen en ella la existencia de esta parte del cuerpo que reputan indispensable; cuando se convencen de que la mujer los ha engañado en este punto, ella se les vuelve inaceptable como objeto sexual. No pueden prescindir del pene en la persona destinada a estimularlos para el comercio sexual, y en el mejor de los casos fijan su libido en la "mujer con pene", el jovencito de femenina apariencia. Los homosexuales son, entonces, personas a quienes el significado erógeno de su genital propio les ha impedido renunciar en su objeto sexual a esta semejanza con la persona propia. En el desarrollo desde el autoerotismo al amor de objeto han permanecido fijados en un lugar más próximo al primero'. Cfr. Analisi della fobia di un bambino di cinque anni (caso clinico del piccolo Hans), en Opere, Boringhieri, Torino, 1972, vol. V, p. 561. El error de Freud es generalizar la hipótesis antes mencionada, que ciertamente no concierne a todos los 'casos' de homosexualidad, sino que su validez relativa se puede encontrar en algunos. En varias de sus obras, Freud tiende a proporcionar la interpretación más 'definitiva' del fenómeno homosexual: sin embargo, de vez en cuando, sus interpretaciones varian. Por lo tanto, ninguna debe ser considerado como la verdad simplemente porque ha sido expuesto en términos objetivos por el Padre del Psicoanálisis. Cada uno debe entenderse solo como una hipótesis, a veces como una mera opinión: solo comparando las diferentes hipótesis e intentando resumirlas iluminadas por un espíritu crítico revolucionario- podemos usar la herramienta psicoanalítica de manera rentable para arrojar luz sobre la cuestión homosexual. 
vuelta $\{$ Wendung\} repentina; el joven no abandona a su madre, sino que se identifica con ella; se trasmuda en ella y ahora busca objetos que puedan sustituirle al yo de él, a quienes él pueda amar y cuidar como lo experimentó de su madre. He ahí un proceso frecuente, que puede corroborarse cuantas veces se quiera, y desde luego con entera independencia de cualquier hipótesis que se haga acerca de la fuerza pulsional orgánica y de los motivos de esa mudanza repentina'75.

Una vez más, Freud ni siquiera menciona lo que más podría interesarnos, a saber, las causas y los mecanismos específicos de tal transformación que conducirian a la identificación con la madre y la afirmación de la homosexualidad en la pubertad. Volveré a esta hipótesis freudiana un poco más profundamente y la discutiré más tarde, cuando me concentre en resaltar el carácter ideológico de la adhesión de Franco Fornari a ella ${ }^{76}$. Por el momento me gustaría subrayar nuevamente la incongruencia presente en el pensamiento de Freud: su teoría sexual encuentra la existencia en cualquiera de las tendencias homoeróticas y en particular en los niños ('polimorfos y perversos') y, por lo tanto, llega al reconocimiento de una homosexualidad congénita; más tarde Freud -como por ejemplo en el pasaje recién citado- se interroga por la génesis de la homosexualidad. Pero si la homosexualidad es congénita, obviamente no tiene sentido tratar de establecer su génesis: más bien, será necesario preguntar qué determina su eliminación entre la mayoría y qué permite la afirmación del deseo homosexual entre unos pocos.

La identificación con la madre, es cierto, está presente en la conciencia de muchos homosexuales masculinos, así como también con el padre (mientras que el hetero generalmente siente conscientemente sólo la identificación con el padre del mismo sexo). Esto acentúa la ambigüedad transexual de nuestro ser-en-devenir, más cercano a la transexualidad profunda que la rígida monosexualidad del hetero; nuestra ambigüedad se acerca más a la forma en que somos cuando

75 ID., Psicologia di massa e analisi dell'To, in Psicoanalisi società, Newton Compton, Roma, 1971, p. 231.

${ }^{76}$ Cfr. cap. VI, par., 5. 
niños. No por nada somos homosexuales, somos locos; y, para un mundo mejor, realmente creo que la 'educación' de los niños debe confiarse a maricas y lesbianas: ¡dejen que los pequeños vengan a nosotros!

También debo decir que, al leer un poema de Pasolini, recordé la interpretación freudiana que he citado aquí (ni veo ni busco asociaciones precisas entre la interpretación de Freud y este poema: he hecho la asociación yo mismo, conectando inmediatamente, en la memoria, una con la otra). Por supuesto, este poema refleja un solo caso, en la que no todos los homosexuales se reconocerán, quizás muy pocos, pero su belleza es tal que encierra en sí misma una verdad muy profunda (y que al menos para mí, en cierto sentido, vale la pena). Por lo tanto, deseo transcribirlo en su totalidad. Se llama la súplica de mi madre.

Es dificil hablar con palabras de hijo

cuando en el corazón bien poco lo parezco.

Tú eres la única en el mundo que sabe de mi corazón

lo que siempre ha sido, antes de cualquier amor.

Por eso lo que debo decirte es horrible

Es dentro de tu gracia que nacen mis angustias,

Eres insustituible, y eso ha condenado

a soledad la vida que me has dado.

Y no quiero estar solo, tengo hambre infinita de amor.

De amor de cuerpos sin alma.

Porque el alma está en ti, eres tú, pero tú eres mi madre y tu amor es mi esclavitud:

Toda mi infancia he sido esclavo de este 
alto, compromiso, inmenso, irremediable.

No habria otra forma de sentir la vida

ni otra perspectiva; pero ya se acabó.

Sobrevivimos: con el desasosiego

de la vida que se rehace por fuera de la razón.

Te suplico, ah, te suplico: no quieras morir.

Estoy aquí, solo contigo, en un futuro abril... ${ }^{77}$

No creo en la identificación exclusiva del homosexual con la madre (y mucho menos en la teoría según la cual el homosexual buscaría en la pareja el sustituto de su propio Yo). Creo, como dije, que la identificación con ambos padres, la existencia de los dos sexos en nosotros está más presente que en el hetero. Sin embargo, una cosa es cierta: el verdadero amor por la madre impide que un hombre acepte la Norma heterosexual que ofende, objetiva y oprime a la mujer. Pero no te impide amar a otras mujeres: y creo que cuanto más se libere la homosexualidad en el mundo, más gays disfrutarán del amor y la comprensión erótica con las mujeres. El amor auténtico por el otro sexo sólo puede ir acompañado de un deseo completo, auto y alo-erótico del propio sexo $^{78}$.

También es cierto que las motivaciones histórico-sociales acercan a las personas homosexuales a los hombres heterosexuales más que a las mujeres, a pesar de que en nosotros siempre existen en cantidad y calidad variable de caso en caso, privilegios y gratificaciones decididamente masculinas, que se expresan en los niveles social, psicológico y a menudo sexual, a pesar de la dureza de la persecución y la marginación -que, por supuesto, nos conciernen a los hombres homosexuales como homosexuales y no como machos.

77 PIER PAOLO PASOLINI, Supplica a mia madre, en Poesia in forma di rosa, Garzanti, Milano, 1976, p. 25.

78 Cfr. cap. V, par. 4. 
Pero ¿en una sociedad en la que la subordinación del sexo femenino está estrechamente vinculada al deseo erótico de la mujer por el hombre (la mayoría de las mujeres son heterosexuales) y a la supremacía masculina en la relación heterosexual, uno no podría hipotetizar que los hombres que generalmente se abstienen de las relaciones sexuales con las mujeres y que, en cualquier caso, no las tratan como objetos sexuales, mientras sienten deseo por el hombre, se aproximan en cierta medida a la condición de la mujer, al menos de forma limitada a algunos de sus aspectos? Un gay sabe bien lo que significa acostarse con un hombre heterosexual, uno de los que generalmente cogen a las mujeres y de vez en cuando van por un culo 'solo para demostrar su potencia normal': él sabe lo que significa ser tratado como un agujero, un objeto sexual en el que el hombre, convencido de su 'superioridad', expresa un deseo mediocre, neurótico y egoísta. Muchos gays, entonces, saben lo que significa andar con ropajes de 'mujer': en una palabra, saben lo que significa ser considerados seres humanos de segunda categoria, como el segundo sexo.

Sin embargo, no se puede establecer hasta qué punto los homosexuales experimentan situaciones similares a las experimentadas por las mujeres. Las situaciones, por otro lado, varían de un caso a otro, y entre los mismos gays los más 'afeminados', las maricas, a menudo sufren la humillación y la violencia que los más viriles, straight, las maricas veladas imaginan solo con terror. Estoy feliz de ser una evidente marica 'femenina': el sufrimiento que esto trae consigo en esta sociedad es al mismo tiempo la medida o si se quiere el espejo de la belleza dura y al mismo tiempo frágil y preciosa de mi vida. Es un gran destino poseer y tratar de vivir con la conciencia tranquila una existencia que la masa regular, en su ceguera idiota, desprecia y trata de sofocar. Un compañero del Fhar (Front Homosexuel d'Action Révolutionnaire) escribió: "Reclamamos nuestra 'feminidad', la misma que las mujeres rechazan, y al mismo tiempo declaramos que estos roles no tienen sentido alguno"79. Por su parte, Daniele Morini admitió:

79 Cfr. Dove è andato il mio cromosomo?, en Fhar, Rapporto contro la normalità, Guaraldi, Rimini, 1972, p. 83. 
'Sé cuánto me costó reconocer mi deseo de marica por lo que es: detrás de ambas quejas (no puedo porque NO soy homosexual / no puedo porque estoy demasiado politizado para tener un deseo alienado) hay otro miedo: descubrirme a mí misma como una mujer enfrentada a un deseo vinculado explícitamente al macho. La negativa a vivir un papel alienado aquí esconde el miedo a lo que pueda revelar vivirlo hasta el final. ¿O el miedo a ser macho?'80.

Para tratar de entender lo que permite la afirmación viva del deseo homosexual entre algunas personas a pesar de la condena social del homoerotismo, creo que es apropiado tener en cuenta el complejo de Edipo completo: es decir, sea en su aspecto 'normal' o 'positivo', o sea en su llamado aspecto 'negativo' o 'invertido'. En otras palabras, debemos tener en cuenta 'el carácter triangular de la situación edípica y la bisexualidad constitucional del individuo' (Freud); yo diría: la transexualidad constitucional del individuo.

De hecho, un análisis en profundidad descubre que el complejo de Edipo es 'duplicado, positivo y negativo, dependiente de la bisexualidad originaria del niño. Es decir que el varoncito no posee sólo una actitud ambivalente hacia el padre, y una elección tierna de objeto en favor de la madre, sino que se comporta también, simultáneamente, como una niña: muestra la actitud femenina tierna hacia el padre, y la correspondiente actitud celosa y hostil hacia la madre. Esta injerencia de la bisexualidad es lo que vuelve tan dificil penetrar con la mirada las constelaciones de las elecciones de objeto e identificaciones primitivas' (Freud) ${ }^{81}$.

Para tener una idea del complejo de Edipo en su totalidad, debemos por lo tanto tener en cuenta las tendencias hetero y homoeróticas del niño. Quien solo tiene en cuenta el aspecto 'positivo' del complejo termina interpretando la infancia (y la pubertad que con frecuencia implica un renacimiento del Edipo) de acuerdo con categorías

80 DANIELE MORINI, La Bella e la Bestia, "Il Vespasiano degli omosessuali", a cura dei Collettivi omosessuali milanesi, giugno 1976, p. 16.

${ }^{81}$ FREUD, L'To e l'Es cit., p. 49. 
exclusivamente heterosexuales: al hacerlo, no puede comprender la complejidad de la situación edípica, ya que la infancia es 'perversa de forma polimorfa' y no solo es heterosexual, ni puede comprender la complejidad de la pubertad, dado que la pubertad, como se sabe, presenta una rica repetición de los deseos homosexuales, a menudo más numerosos e intensos que los heterosexuales, en el contexto del despertar parcial del Eros que lo caracteriza. ¿Por qué el niño, cuya disposición polimorfa 'indiferenciada' es conocida, debe estar celoso de la madre y sentir sentimientos de rivalidad hacia el padre y no, simultáneamente, lo contrario? ¿Y la niña celosa de su padre en lugar de su madre? El psicoanálisis en sí mismo -como veremos más tarde ${ }^{82}$ reconoce en los celos, entre los adultos heterosexuales, una manifestación enmascarada de deseo homoerótico: esto significa que, por ejemplo, en el caso de un hombre, esto prueba que los celos hacia la mujer amada que está siendo cortejada por otro, inconscientemente, él desea a ese otro. Pero la infancia está mucho menos enmascarada: la homosexualidad aún no se ha eliminado, por lo que en los celos edípicos 'positivos' del niño por la madre, uno también debe ser capaz de reconocer el deseo por el padre: el llamado aspecto 'positivo' y el 'negativo' del complejo se entrelazan.

Freud agrega: 'la experiencia analitica muestra que, en una cantidad de casos, uno u otro de los componentes de aquel desaparece hasta dejar apenas una huella registrable, de suerte que se obtiene una serie en uno de cuyos extremos se sitúa el complejo de Edipo normal, positivo, y en el otro el inverso, negativo, mientras que los eslabones intermedios exhiben la forma completa con participación desigual de ambos componentes. A raíz del sepultamiento del complejo de Edipo, las cuatro aspiraciones contenidas en él se desmontan y desdoblan de tal manera que de ellas surge una identificación-padre y madre; la identificación-padre retendrá el objeto-madre del complejo positivo y, simultáneamente, el objeto-padre del complejo invertido; y lo análogo es válido para la identificación-madre. En la diversa intensidad con que se

${ }^{82}$ Cfr. cap. III, par. 4. 
acuñen sendas identificaciones se espejará la desigualdad de ambas disposiciones sexuales'83.

No creo que el significado diferente asumido por las dos identificaciones dependa solo del mayor o menor peso de las dos predisposiciones sexuales (la homosexual y la heterosexual): estoy seguro de que también depende de la educastración, o de la represión socio-familiar que empuja con fuerza a que el niño se identifique con el padre y renuncie al 'objeto' masculino y que la niña se identifique con la madre, renunciando al 'objeto' femenino.

Quizás se pueda suponer que quien se vuelve homosexual, gracias a la riqueza particular de su predisposición al homoerotismo, no renuncia al 'objeto' masculino (al 'objeto' paterno) si es hombre, o al 'objeto' femenino ('objeto' materno) si es femenino: y que la fuerza de la disposición homosexual congénita se ve exacerbada por una cierta tendencia (no importa si es consciente) del progenitor del mismo sexo a establecer una relación homoerótica con el niño, una relación afectiva particular.

En general, debido al tabú anti-homosexual (y del tabú anti-incesto), la elección del objeto amoroso del hijo por el padre es castrada, negada por el propio padre; y la de la hija por la madre negada por la propia madre. Esto conduce 'normalmente' al predominio de la identificación con el padre, en el hombre, y al predominio de la identificación con la madre, en la mujer: como explica Freud, la identificación adquiere un valor sustitutivo con respecto al 'objeto' prohibido - y el 'objeto' más estrictamente prohibido es el del complejo de Edipo 'invertido'. Tal identificación prevalente con el padre del mismo sexo lleva a mantener solo la elección del objeto de tipo heterosexual, ya que se basa sobre todo en la represión del deseo homoerótico y porque el padre introyectado por la identificación es heterosexual. Esto explicaría la eliminación de la homosexualidad en los llamados individuos 'normales'.

83 FREUD, L'Io e l'Es, cit., p. 50. 
Se puede pensar, en cambio, que el deseo homosexual no es eliminado por aquellos que encuentran en el padre del mismo sexo una cierta correspondencia en su investudura objetal homoerótica: aquellos en cuya infancia, por lo tanto, la tendencia edipica 'negativa' o 'inversa' no se ve brutalmente reprimida, pero encuentra un cierto grado de expresión en la dialéctica de las relaciones familiares. La renuncia a los 'objetos' del sexo ‘opuesto' dependería de la identificación silenciada con el padre del mismo sexo y, por lo tanto, de su comportamiento heterosexual, y también del sentimiento de culpa, o más bien de la internalización de la condena social que afecta a aquellos que no se identifican completamente con los padres de su propio sexo (con el modelo patriarcal predeterminado del hombre o la mujer), que no se ajustan a la Norma. El sentimiento de culpa nos induce a sentirnos inferiores en comparación con las personas 'normales', indignas de una elección de objeto considerada socialmente superior, positiva, 'normal'. Por lo tanto, se puede plantear la hipótesis de que la eliminación del deseo por el otro sexo en los homosexuales se debe a la condena social de la homosexualidad, lo que lleva al homosexual a sentirse culpable y, por lo tanto, indigno de la elección definida 'normal', incapaz de complacer a las personas del otro sexo; además, la represión obliga al homosexual a luchar constantemente contra los perseguidores externos y contra la culpa inducida, el perseguidor interno, para defender -solo contra todos- su propia elección 'anómala', su propio deseo homoerótico, concentrando toda su energías libidinal en ella. Por lo tanto, la liberación de la homosexualidad en la esfera social y la eliminación del sentimiento de culpa (de falsa culpa) conduciría -y estoy convencido de esto- a que los homosexuales re-descubran su deseo erótico por las personas del otro sexo y al descubrimiento de la atracción especial que las personas del otro sexo sienten por ellos.

Hubiera preferido no tener que obligar al lector a seguirme en este tratamiento complicado e hipotético, en varios puntos más que carentes: pero el argumento, como he dicho, es dificil y pocos se han dado el tiempo de explorarlo. También podría presentar otras hipótesis... pero creo que ninguna lo suficientemente interesante como 
para ofrecer al público. Creo que la liberación práctica, sobre todo, favorecerá el análisis: sólo la emancipación universal de la homosexualidad realmente puede arrojar luz sobre la historia de su represión y de su retorno siempre renovado, a pesar de la persecución, a lo largo de los siglos.

El movimiento de mujeres ha descubierto la importancia de la relación de amor de cada mujer con su madre, del complejo de Edipo 'invertido'. En un artículo de 1974, algunas feministas de Milán revelan que "la homosexualidad, en un sentido amplio, como una relación con la madre, es la relación fundamental primaria de todas las mujeres'. Melanie Klein 'insiste en las tendencias edipicas que 'naturalmente' empujan a la niña hacia su padre, pero luego no explica por qué el padre a menudo se internaliza como un padre sádico, si no regresa a la frustrante relación con la madre". Resulta que la rivalidad con el sexo masculino es para las mujeres una consecuencia de la relación homosexual fundamental con la madre. De hecho, "la madre decepciona a la niña no porque 'incorpore el pene paterno', sino porque está poseída por la ley del padre. A través del deseo de la madre, el 'pene' adquiere un gran prestigio a los ojos de la niña, se convierte en objeto de admiración y deseo". "Solo la posesión del 'pene' garantiza la omnipotencia y, por lo tanto, el poder sobre la madre (poder de poseerla y destruirla). La identificación / asimilación al macho, movida por la envidia del pene, precede al amor por el macho". "En la niña, los impulsos sádicos pronto se asocian con la fantasía de poseer un 'pene' destructivo, mientras que el objeto de deseo y agresión sigue siendo la madre. Con el hombre, en cambio, establece una especie de 'complicidad pederasta' por la cual, o bien asume él mismo carácter masculino, o repite, a través de la seducción y el acto sexual, la introyección simbólica del pene. El amor heterosexual es, por lo tanto, para las mujeres, generalmente la re-confirmación de la posición masculina. En este punto, sería correcto modificar la afirmación habitual de que la mujer busca a la madre en el hombre, y decir en 
cambio que a través del amor al hombre -la repetida reapropiación del pene- la mujer apunta en realidad a la posesión de la madre" 84 .

Desde el punto de vista gay, así como desde el punto de vista feminista, no se puede hablar de un complejo de Edipo sin proporcionar una refundación completa de las teorías que le conciernen, sin tener realmente en cuenta el complejo en su totalidad. Según Deleuze, uno no debería 'creer que es suficiente con la homosexualidad para salir de las categorias psicoanalíticas clásicas: Edipo - castración - pulsión de muerte'85. Pero, aunque reconoce que la homosexualidad, de manera similar a la heterosexualidad, también se basa en una concepción arraigada de la diferencia entre los sexos, una diferencia que encuentra su fundamento en el contexto de la triangulación edipica y como la transexualidad de la profunda impugnación, nosotros, los homosexuales, no nos reconocemos en la categoría psicoanalitica clásica de Edipo, ya que la homosexualidad, de cierta manera, niega a Edipo: 'la manifestación inmediata del deseo homosexual se opone a las relaciones de identidad, a los papeles necesarios que impone Edipo para garantizar la reproducción de la sociedad. La sexualidad reproductora es también la reproducción del Edipo; la heterosexualidad familiar no sólo garantiza la producción de hijos sino, sobre todo, la reproducción de Edipo como diferenciación entre los padres y los hijos' (Guy Hocquenghem). El deseo homoerótico amenaza la reproducción edípica: 'El deseo homosexual es el inengendrante-inengendrado, el terror de las familias en la medida en que se produce sin reproducirse'86.

Al tratar con la afirmación de la heterosexualidad, hemos visto cómo su supremacía (que se determina a través de la fase edípica) se basa en la represión de las tendencias homoeróticas. La lucha homosexual

84 ALCUNE FEMMINISTE MILANESI, Pratica dell'inconscio e movimento delle donne, "L'Erba Voglio", n. 18-19, ottobre 1974 - gennaio 1973, pp. 12-23.

85 GILLES DELEUZE, discurso realizado en la Conferencia de Estudio celebrada en Milán los días 8 y 9 de mayo de 1973 y organizada por el colectivo de Semiótica y Psicoanálisis, en Psicanalisi e politica, Feltrinelli, Milano, 1973, p. 45.

86 GUY HOCQUENGHEM, Le désir homosexuel, Editions Universitaires, Paris, 1972, p. 72 . 
revolucionaria, por lo tanto, lucha contra una forma de represión que yace detrás de Edipo. Niega el Edipo porque niega sus premisas. E1 mismo Deleuze, con entusiasmo benevolente, admite: 'No es que haya menos potencial revolucionario en ciertos grupos homosexuales. Creo que no es simplemente porque son homosexuales, más que eso, porque, a través de su homosexualidad, han podido cuestionar el problema de las diferencias entre los sexos. Y a través de este cuestionamiento, se vuelven capaces, como marginales, de formular, de hacerse cargo del problema del deseo sexual en general'87. Muchas gracias. Nosotras, maricas revolucionarias, sabemos cómo ver en el niño no tanto a Edipo, o al futuro Edipo, sino al ser humano potencialmente libre.

Nosotras, sí, podemos amar a los niños. Podemos desearlos eróticamente respondiendo a su deseo del Eros, podemos captar la sensualidad embriagadora que dan a la cara y abrir los brazos, podemos hacer el amor con ellos.

Esta es la razón por la cual la pederastia ${ }^{88}$ está tan severamente condenada: dirige mensajes amorosos al niño que la sociedad, a través de la familia, traumatiza, educa, niega, dejando caer la grilla edípica en su erotismo. La sociedad represiva heterosexual obliga al niño al periodo de latencia; pero el período de latencia es solo la introducción letal a la cadena perpetua de una 'vida' latente. La pederastia, en cambio, 'es una flecha de lujuria lanzada hacia el feto' (Francesco Ascoli).

87 DELEUZE, intervención citada, p. 45.

88 Por pederastia me refiero al deseo erótico de los adultos por los niños (de ambos sexos) y las relaciones sexuales entre adultos y niños. La pederastia (en el sentido apropiado) y la pedofilia se usan comúnmente como sinónimos. 